\begin{tabular}{c}
\hline Review of \\
ECONOMICS \\
and \\
INSTITUTIONS
\end{tabular}

\title{
Long Live Patents: the Increasing Life Expectancy of Patent Applications and Its Determinants
}

\author{
Nicolas van Zeebroeck ${ }^{凶}$ \\ ULB, Université Libre de Bruxelles
}

\begin{abstract}
Relying on a comprehensive dataset including detailed information on all patent applications filed to the EPO from 1980 to 2000 and on the renewal of those of them that were granted, this paper presents the first survival time analysis of the determinants of patent length. The results are twofold: first, they clearly establish that the life expectancy of patent rights has significantly increased over the past decades despite a small decline in the average grant rate. Second, they show that some filing strategies very strongly influence the overall length of patents, possibly due to induced delays in the examination process. This suggests that such strategies may result in higher and longer lasting legal uncertainty on the markets, with unknown consequences on the dynamic efficiency of the patent system.
\end{abstract}

JEL classification: 031; 034; 050

Keywords: patent length, patent value, renewals, granting process, survival time analysis

$\square$ Address: Université Libre de Bruxelles (ULB) - Solvay Brussels School of Economics and Management (SBS-EM) - ECARES: Av. Roosevelt 50 (CP114/4) । B-1050 Brussels, Belgium. (Phone +32.2.650.33.75, Email: Nicolas.van.Zeebroeck@ulb.ac.be).

\section{Recommended Citation}

van Zeebroeck, N. (2011). Long Live Patents: the Increasing Life Expectancy of Patent Applications and Its Determinants. Review of Economics and Institutions, 2(3), Article 5. doi: 10.5202/rei.v2i3.41. Retrieved from http://www.rei.unipg.it/rei/article/view/41 


\section{Introduction}

The empirical literature has been prolific around the issues of patent length and geographical scope; the length of patent rights is in particular an issue of considerable importance in the design of patent systems, and its optimality has been intensively discussed in the literature. Since obtaining patent protection in any additional country or maintaining a patent enforceable in one country in particular is costly, research scholars have long assumed that patents protected in many countries (Putnam, 1996) or maintained for a long period (Pakes and Schankerman, 1984) carry more private value to their holders than those that are protected in a small number of countries or are abandoned very quickly. But very few patents are maintained until their statutory term of 20 years and the length of patents is in effect a decision of the patent holders. However, little is known to date on the evolution in the overall duration of patent rights, or on the factors that influence this duration throughout their lifetime.

Taking advantage of a unique dataset containing detailed data on all validations and renewals in Europe, the main objective of this paper is therefore to investigate the evolution and determinants of patent length. This study is therefore exploratory in nature, but aims at contributing to our understanding of the various factors that may affect the life expectancy of patents. Given the provisional rights conferred to pending applications by virtue of the European Patent Convention, it looks essential to not only consider the length of patent rights once granted, but their entire life (from filing to lapse) as a more comprehensive measure of their entire period of enforceability. Given the amount of legal uncertainty that pending applications may induce on the markets, this sounds even more critical.

This research is original in several respects: first, it investigates the overall length of patent rights from filing to lapse instead of considering exclusively the pre- or post-grant life of patents; second, it uses a comprehensive database with all patent applications filed to the EPO over a 20 years period; and third, it explores the impact of a wide range of factors on patent length, including filing strategies, value indicators, complexity indicators, and ownership structures.

The main results of this paper are twofold. First of all, they clearly establish that the life expectancy of patent rights in Europe has significantly increased over the eighties and the nineties despite an apparent (but slow) decline in the average grant rate and the overall drop in different value indicators observed or suspected by different authors.1 ${ }^{1}$ This evolution has however not been equal across technology fields. Secondly, the most striking results of this exploratory analysis show that filing strategies considerably affect the length of patents, possibly because they shape the examination

1 See e.g. Jaffe and Lerner (2004), Guellec and van Pottelsberghe (2007) and van Zeebroeck (2011). 
process. Perhaps more expectedly, more important or complex patents also tend to live longer, providing additional empirical support to the widely shared view of patent renewals as value indicators.

These results have some important policy implications. First, the apparent inflation in length of patent rights suggests that exclusive rights are enforced over longer periods nowadays and therefore delay the expected dynamic efficiency of patents, everything equal. It is not possible to conclude from our results whether this has net detrimental effects on social welfare, but this effective dilatation of patents is appealing enough to deserve further investigation. Second and foremost, the results suggest that the length of patents may be considerably expanded by specific filing strategies that are in control of the applicants. This suggests that applicants may sometimes use certain procedural possibilities to postpone the granting of their applications. And this is important as it creates more uncertainty on the markets. The surge in patenting observed throughout the world over the past decades (see e.g. Kortum and Lerner, 1999), combined with the inflation in the size of applications (see Archontopoulos et al., 2007 and van Zeebroeck et al., 2009), has indeed induced a considerable increase in the workload of most patent offices, resulting into roaring stocks of pending applications. Our results suggest that part of the backlog may actually be aggravated by some specific applicant strategies.

Our teaching in this paper is organised as follows: section 2 summarizes the existing literature. Section 3 presents statistical evidence on the evolution of patent length. Potential explanatory factors are presented in section 4 , whereas the empirical implementation is introduced in section 5, the results of which are discussed in section 6 . Section 7 concludes.

\section{Patent Length: an Indicator of Patent Value and a Quest for Optimality}

The length of patents, i.e. the period over which the exclusive rights they entitle can be enforced, have been considered as indicators of the private value of patents for long, on the grounds that the costs incurred to maintain patents year after year would only be paid for by firms when they expect a net benefit from their patent. The model proposed by Pakes and Schankerman (1986) suggests that the initial return on a patent is decreasing geometrically over time, due to a decay rate of the patent returns, which depends on the effectiveness of the patent protection (the dissipation rate of the monopoly rent) and on the obsolescence rate of the patented knowledge.

In their model, Schankerman and Pakes (1986) focus on the decision to renew granted patent rights or not, and therefore only consider the annuities to be paid for each year of maintenance beyond the actual grant of a patent, which depend on the year of filing of the patent and on its age. This is because annual fees required by patent offices may be revised by the of- 
fice and because in most offices, they increase with the year of renewal of the patent. As long as the rents from a patent exceed the costs of one extra renewal annuity, the firm will renew the patent, up to the statutory limit, which is 20 years from the date of filing in most countries. As soon as it does no longer hold, the firm will cease to pay the renewal fees and the patent will lapse in the public domain.

On these grounds, an extensive literature has relied on renewals as indicators of the private value of patents..$^{2}$ This strand of literature has either used renewals to estimate the value of patents or to produce value weighted patent counts.

The present paper claims that the same line of reasoning holds for the entire length of patents, from their filing till their lapse. Indeed, annuities are also required by patent offices (not to mention the legal direct and indirect costs of patent examination) to file then to maintain each application alive up to their grant. Beyond this point in time, validation fees are due that can be seen as the first of the annuities in the preceding model..$^{3}$

Most empirical studies on the length of patent rights focus either on the examination process (time to decision) or on the renewal term of granted patents. Papers from the former group include Harhoff and Wagner (2009), Popp et al. (2004), Régibeau and Rockett (2003), and Yang (2007), and aim at understanding the drivers of the time required to examine and grant patents in different offices. The main results from these papers are that more complex patents imply longer decision lags, that the examination duration typically depends upon the workload faced by the patent office, that an endogenous behaviour of applicants to slow down the process may sometimes be suspected, but that differences across technologies are very important. Régibeau and Rockett (2003) build a theoretical model to link grant lags with the importance of patent applications and find that the welfaremaximising patent approval delay decreases over time, conditional on the importance of innovations, and that controlling for a patent's position in the new technology cycle, the optimal examination time should decrease with the importance of patents.

The latter group of papers focuses on the determinants of the renewal of patents as an indicator of patent value. The determinants of patent renewals have been subject to less empirical modelling. To the best of our

\footnotetext{
2 See Pakes and Schankerman (1984); Pakes (1986); Pakes and Simpson (1989); Lanjouw et al. (1998); Schankerman (1998); O'Donoghue et al. (1998); Cornelli and Schankerman (1999); Deng (2005); Bessen (2008); van Zeebroeck and van Pottelsberghe (2008).

3 Note that the exact sequence of annuities paid for by applicants is more complex to determine in this extended view, since procedural fees up to grant depend on various factors, including the size and form of the application (number of claims and pages, electronic v. manual filing, etc.) and of different potential events in the course of the examination. Upon grant, the cost of validation and renewals will depend on the number of countries in which the patent will be enforced. For more details on the cost of patenting in Europe, see van Pottelsberghe and François (2009).
} 
knowledge, the only examples found in the literature focus on very small and selective samples of patents and consider a very limited number of potential factors. The results essentially suggest a positive association between forward citations received and life expectancies (Maurseth, 2005) and that patents licensed tend to be maintained longer than non-commercialized patents (Svensson, 2007).

However, there are strong arguments for considering the length of European patent applications in their entirety, from their filing to their decision or lapse. The fact that the EPC entitles the same provisional rights to pending patent applications in all designated states as a granted patent, makes pending applications virtually as enforceable (at a much lower cost) as any valid patent grant. $\left.\right|^{4}$ Therefore, when investigating the determinants of patent length, there is little reason for discarding non granted applications or for focusing only on the post-grant destiny of patents. One additional reason for paying as much attention to refused and withdrawn applications as to grants is that despite their failure to turn into valid patent rights, such applications have conferred their owners with some provisional exclusive rights for the entire duration of the examination proceedings. This protection may appear as illegitimate ex-post, not to mention the legal uncertainty induced during their pendency period..$^{5}$

The main originality of this paper is to investigate the length of all patent applications filed to the EPO, no matter they were granted or not, and its potential determinants. Our main objective is therefore to analyse the time elapsed between the filing of an application and its ultimate fall into the public domain. This lapse of patent rights may be due to different events: a decision not to patent it, a revocation following opposition proceedings, a decision not to pay renewal fees any longer, or the reach of the statutory limit of 20 years. At the EPO, some $30 \%$ of all patent applications filed are withdrawn by their applicant, 5\% are refused by the Office, and about $65 \%$ are accepted for grant, from which $60 \%$ are validated in different European countries and $5 \%$ are never validated and therefore lapse $a b$ initio.

\footnotetext{
${ }_{4}^{4}$ As the costs incurred during the granting process are very limited compared with the amount of renewal fees needed to maintain a granted patent in many countries, and as provisional protection may even be extended to the entire EPC area for free (since as of the $7^{\text {th }}$ designated State onward, all member states are assumed to be designated), it is sometimes in the interest of patentees to face as long pendency times as possible, especially when they know their chances to get a patent granted to be low or when they would like to enjoy an abusively large scope of protection for the longest possible time.

${ }^{5}$ It is beyond the scope of this paper to dissert on the optimal duration of the granting process to establish the proper balance between the benefits of a careful examination of patents to maximize the legal certainty and its social costs in terms of potential abusive behaviours. For such a discussion, see Gilbert and Shapiro (1990), Scotchmer (1999), and Régibeau and Rockett (2003).
} 


\section{Measuring Patent Length}

This paper focuses on all patent applications filed to the EPO between 1980 and 2000, about 1.2 million observations in total. Detailed data on all patent applications were obtained by merging an extraction from the main EPO database kindly provided by the Office and the PATSTAT database (EPO, 2006) with Triadic Patent Families (OECD, 2004). Together, these databases allowed the construction of all grant decision variables (including decision lags) and most explanatory variables (presented in the next section). In addition, detailed renewal and lapse data on all European patents from all contracting States (except Italy) were provided by the EPO, allowing the computation of the entire patent length.

However, measuring the length of each patent right is not as straightforward as it may sound as it depends first on the outcome and second - at least for granted patents - on the geographical scope considered. For refused, withdrawn and revoked applications, this measure is relatively simple: it is a mere difference between the date of filing and the date of withdrawal, refusal or revocation. For granted patents however, the maintenance period requires some choices to be made as discussed in van Pottelsberghe and van Zeebroeck (2008). European patents may indeed be validated in any contracting State, but from then on split into a set of national patents that will live on their own. Two approaches to this problem are proposed in van Zeebroeck (2011): the Single Renewal Approach (SRA) consists in measuring the longest renewal reached in any EPC Contracting State, and the Complete Renewal Approach $(C R A)$ consists in observing the shortest common renewal term over a given set of countries.

Both approaches are defensible, as they will both capture for how long the patent holder is willing to maintain his exclusive rights in the countries where he obtained them, but both will do it with some noise. The main difference between the two approaches lies with what it is that one really wants to measure: the CRA approach will rightly reflect the period during which the patent has sufficient value to its holder to incur the costs of maintaining its entire scope of protection. But this approach will therefore not account for the relative size of the market that is given up by letting the patent lapse in a given country while it is being renewed in others. If the patent lapses in fact in a relatively small economy but is maintained in bigger countries, it may suggest that its intrinsic value is intact. With other words, the CRA will treat minor adjustments in scope and complete abandonments likewise. On the contrary, the SRA approach is based on the idea that so long as the patent is maintained in at least one market, it suggests that the patent still carries sufficient value to its holder and is probably still being exploited. This is the view that is adopted in this paper, as it appears more appropriate to study survival rates: a patent is dead only once is has lapsed in all countries. Descriptive statistics based on the alternative CRA approach are 
nonetheless reported and indicate that the mean difference between the two approaches is about 1 year.

Summary statistics for the main variables in the dataset are indeed reported in Table 1. However, one additional issue with patent length is the right truncation that affects a significant share of the data. This concerns either pending applications (representing $9 \%$ of the dataset) for which a decision was still expected at the time the data on decisions were extracted, that is on March 10, 2006, or patent grants that were still active at the time patent renewals were extracted and have not reached their statutory term yet (about $45 \%$ of all granted patents). For truncated observations (pending applications and active patents), the entire life duration will be computed as the difference between the date of extraction of the data (March 10, 2006) and the date of filing, that is, the age reached to date by each application or grant. An ad-hoc variable has been constructed to indicate which reason made the patent lapse. This variable is set to zero for truncated observations, denoting the absence of observed failure. This issue, which affects overall about one third (34\%) of the dataset, will be discussed later on.

Table 1 - Summary Statistics of Patent Life Indicators

\begin{tabular}{lcccccc}
\hline \hline Variable & Unit & Obs. & Mean & S.D. & Min & Max \\
\hline Survival Times & & & & & & \\
Entire life duration (from filing to lapse) - CRA & Years & 1189058 & 7.16 & 3.81 & 0.00 & 20.00 \\
Entire life duration (from filing to lapse) - SRA & Years & 1189058 & 8.15 & 4.56 & 0.00 & 20.00 \\
Entire life duration is truncated & Y/N & 1189058 & 0.34 & 0.47 & 0.00 & 1.00 \\
& & & & & & \\
Grant Decisions & & & & & & \\
Deemed Withdrawn & Y/N & 1189058 & 0.21 & 0.41 & 0.00 & 1.00 \\
Withdrawn & Y/N & 1189058 & 0.06 & 0.25 & 0.00 & 1.00 \\
Refused & Y/N & 1189058 & 0.03 & 0.18 & 0.00 & 1.00 \\
Granted & Y/N & 1189058 & 0.61 & 0.49 & 0.00 & 1.00 \\
Lapsed ab initio (granted but not validated) & Y/N & 1189058 & 0.04 & 0.20 & 0.00 & 1.00 \\
Granted and validated & Y/N & 1189058 & 0.57 & 0.50 & 0.00 & 1.00 \\
Pending on March 10, 2006 & Y/N & 1189058 & 0.09 & 0.28 & 0.00 & 1.00 \\
\hline Sample: all applications filed to the EPO between 1980 and 2000 & & & & &
\end{tabular}

From this table, it can be noticed that European patent applications live on average about 8 years ${ }^{6}$ Figure 1 shows how this duration has evolved in the eighties and nineties using the SRA approach, although the apparent decline from 1986 onward is a spurious effect of right truncation.7 Statistics on grant decisions reveal that about $21 \%$ of all applications have been deemed withdrawn, ${ }^{8} 6 \%$ were explicitly withdrawn, 3\% were refused, 9\% were still pending, and $61 \%$ were granted. Within those $61 \%$ of patents granted, $4 \%$

\footnotetext{
${ }^{6}$ Note however that this figure is an underestimation of the actual life expectancy of European patent rights as it is affected by the $34 \%$ of truncated observations in the dataset.

7 Figure A1 in the appendix provides the same using the alternative CRA approach and exhibits similar patterns.

8 i.e. The applicant did not explicitly withdraw her application but failed to comply with the procedural requirements to pursue the examination procedure.
} 
were lapsed $\mathrm{ab}$ initio and the remaining $57 \%$ were properly validated in at least one EPC contracting State.

\section{Figure 1 - Evolution of EPO Patent Applications Entire Life (from Filing to Lapse) Using the SRA Approach}

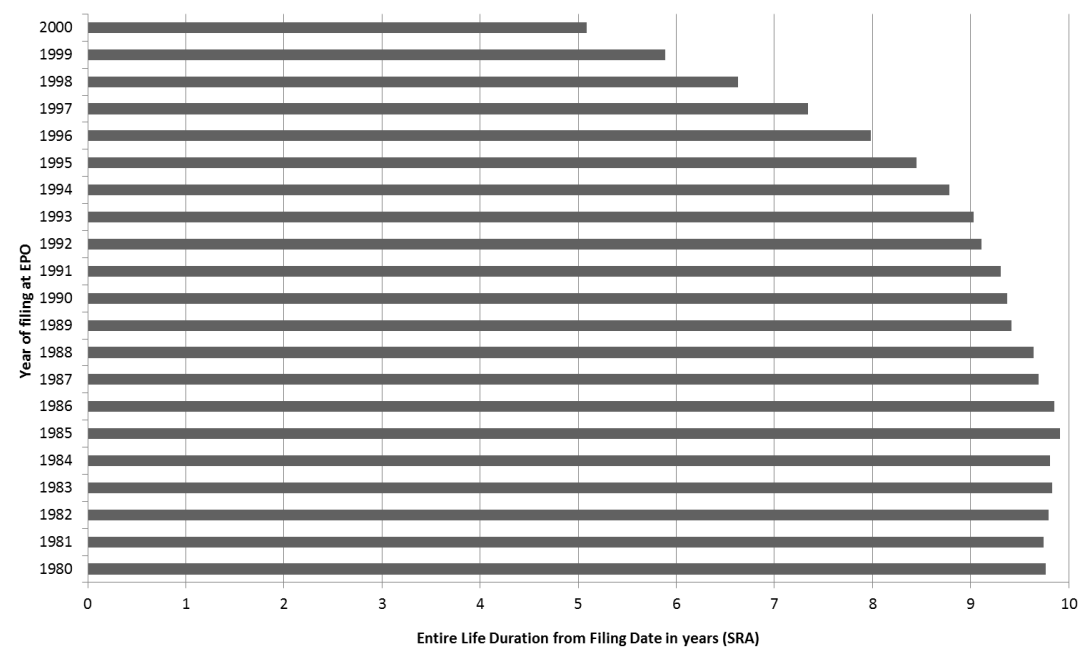

A frequent concern in the patent system is that there seems to be a decline in the value or quality of applications (as suggested e.g. by Jaffe and Lerner 2004, Minoo 2006, Guellec and van Pottelsberghe 2007). This conjecture finds additional support in Figure 2, showing that applications withdrawn have increased by about $25 \%$ on average between the early eighties and the late nineties, mainly at the expense of a lower grant rate.

Figure 2 - Decisions on Patent Applications Filed to the EPO

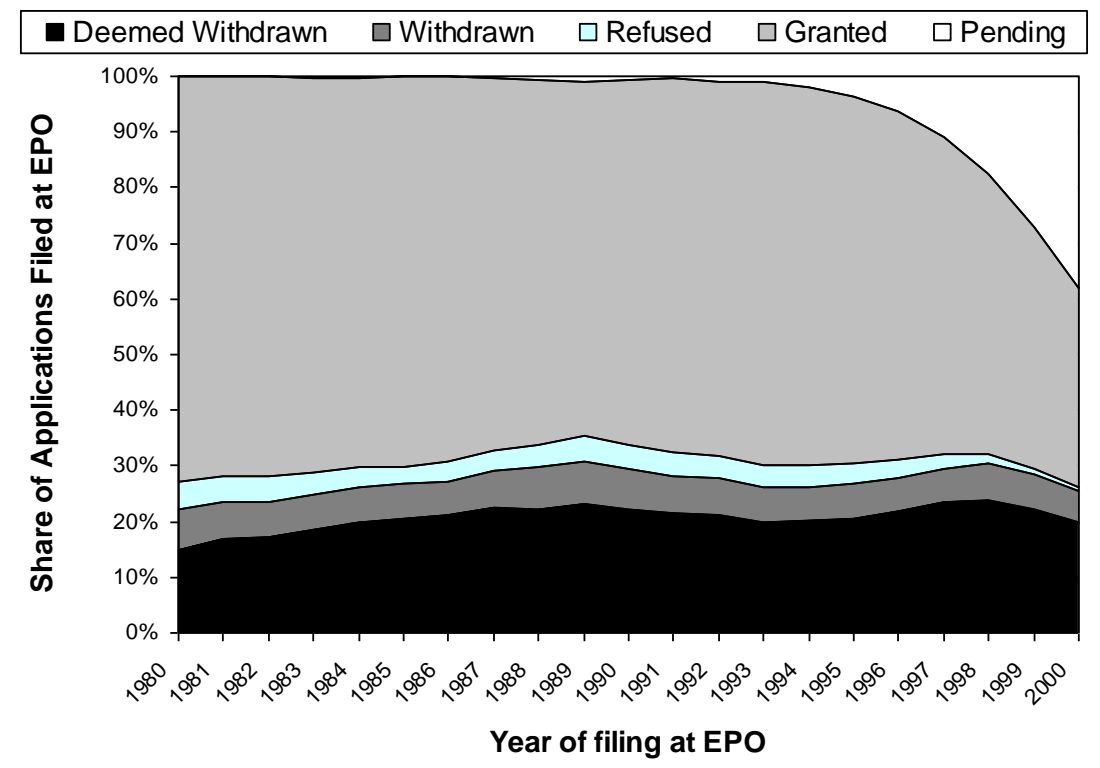




\section{Potential Explanatory Factors}

This paper explores the potential determinants of patent length. Different groups of factors are included in the model as summarized in Table 2. Summary statistics are reported in Table 3.

\section{Table 2 - Overview of Explanatory Variables Used in Econometric Estimations}

\begin{tabular}{|c|c|c|}
\hline Group & Determinant & Notation \\
\hline \multicolumn{3}{|c|}{ Filing strategies (FS) } \\
\hline \multirow[t]{2}{*}{ Filing routes } & PCT vs. EP Direct & $R T E \_P C T$ \\
\hline & Accelerated Search Request & $R T E \_A C C S R C$ \\
\hline \multirow[t]{5}{*}{ Drafting styles } & Number of claims in application filed & $D R \bar{F}_{-} C L A I M S$ \\
\hline & Number of priorities listed in application & $D R F \_P R I O$ \\
\hline & Number of EP equivalents & DRF_EQUIV \\
\hline & Application followed by divisionals & DRF_HASDIV \\
\hline & Application is a divisional & $D R F \_I S D I V$ \\
\hline \multicolumn{3}{|c|}{ Patent characteristics (PC) } \\
\hline \multirow[t]{2}{*}{ Value } & Forward citations (after 5 years) & IMP_FWDCIT5 \\
\hline & Triadic & $I M P_{-} T R I A D I C$ \\
\hline \multirow[t]{4}{*}{ Complexity } & Number of backward patent citations & $C M P_{-} B P C$ \\
\hline & Number of backward non-patent citations & $C M P_{-} N P C$ \\
\hline & Number of IPC classes (at different levels) & $C M P_{-} I P C$ \\
\hline & Number of inventors listed & $C M P_{-} I N V$ \\
\hline \multicolumn{3}{|c|}{ Patent Ownership (PO) } \\
\hline & Co-Applicants & APP_MULTIPLE \\
\hline & Cross-border ownership & $A P P_{-} C B O W N$ \\
\hline & Portfolio size & $A P P_{-} C U M U L$ \\
\hline & Inexperience & APP_OCCAS \\
\hline
\end{tabular}

Stevnsborg and van Pottelsberghe (2007) and van Zeebroeck and van Pottelsberghe (2011a) identify different dimensions of a patent filing strategy (some of which are based on Harhoff, 2006). They pertain to the route followed by each application to reach the EPO (PCT option, RTE_PCT), filing of a request for accelerated search (RTE ACCSRC), and different characteristics of the drafted document as filed: number of claims (DRF_CLAIMS), number of priorities merged to form the application (DRF PRIO), number of non-divisional EP equivalents (separate EP filings having at least one priority in common, DRF_EQUIV), whether the application was split into divisional filings (DRF_HASDIV), and whether it is a divisional filing in itself (DRF_ISDIV). Table 3 shows that about $31 \%$ of applications filed in the period 1980-2000 were filed through the PCT option and that only $2 \%$ of applications have been subject to an accelerated search request. In terms of drafting features, the average number of claims per application in the sample is slightly over 13 (with a maximum of 592), patent filings have on average one priority filing (zero for EP first filings and up to 136 for second filings), and 0.15 equivalents at the EPO. Finally, $3 \%$ of applications are 
parents of divisionals and a similar share are divisionals (suggesting that parents give on average rise to only 1 divisional filing). Van Zeebroeck and van Pottelsberghe (2011a) have shown that most these dimensions of patent filing strategies have gained in popularity over the past decades.

Table 3 - Summary Statistics of Potential Explanatory Factors

\begin{tabular}{lcrrrrr}
\hline Variable & Type & Obs. & Mean & S.D. & Min & Max \\
\hline Filing routes & & & & & & \\
RTE_ACCSRC & Y/N & 1189058 & 0.02 & 0.13 & 0.00 & 1.00 \\
RTE_PCT & Y/N & 1189058 & 0.31 & 0.46 & 0.00 & 1.00 \\
Drafting & & & & & & \\
DRF_CLAIMS & Discrete & 1188907 & 13.33 & 10.81 & 1.00 & 592.00 \\
DRF_PRIO & Discrete & 1189058 & 1.16 & 0.87 & 0.00 & 136.00 \\
DRF_EQUIV & Discrete & 1189058 & 0.15 & 0.65 & 0.00 & 39.00 \\
DRF_HASDIV & Y/N & 1189058 & 0.03 & 0.16 & 0.00 & 1.00 \\
DRF_ISDIV & Y/N & 1189058 & 0.03 & 0.16 & 0.00 & 1.00 \\
Value & & & & & & \\
IMP_TRIADIC & Y/N & 1189058 & 0.56 & 0.50 & 0.00 & 1.00 \\
IMP_FWDCIT5 & Discrete & 1187863 & 0.47 & 1.10 & 0.00 & 70.00 \\
Complexity & & & & & & \\
CMP_BPC & Discrete & 1137261 & 4.49 & 2.90 & 0.00 & 125.00 \\
CMP_NPC & Discrete & 1137261 & 0.95 & 1.81 & 0.00 & 170.00 \\
CMP_INV & Discrete & 1189058 & 2.33 & 1.68 & 0.00 & 49.00 \\
CMP_IPC4 & Discrete & 1184888 & 1.51 & 0.78 & 1.00 & 13.00 \\
Ownership & & & & & & \\
APP_MULTIPLE & Y/N & 1189058 & 0.06 & 0.24 & 0.00 & 1.00 \\
APP_CUMUL & Discrete & 1189049 & 364.22 & 853.19 & 0.00 & 6904.00 \\
APP_OCCAS & Y/N & 1189049 & 0.17 & 0.37 & 0.00 & 1.00 \\
APP_CBOWN & Y/N & 1189058 & 0.10 & 0.30 & 0.00 & 1.00 \\
\hline \hline
\end{tabular}

The second group of explanatory variables is made of two sets of patent characteristics frequently found in the literature on patent value (see van Zeebroeck and van Pottelsberghe, 2011b): value indicators and complexity indicators. The former set includes whether the application is triadic (i.e. has been filed or granted at the USPTO and the Japanese Patent Office, IMP_TRIADIC) and the number of forward citations received within 5 years from the date of publication (IMP FWDCIT5). Table 3 shows that about 56\% of all EPO applications are triadic and that they received on average 0.47 citations within 5 years. Whereas the share of triadic applications at EPO has remained stable since the mid-eighties, the number of forward citations has surged over the past decades, although this evolution might reflect changes in scale rather than a real increase in the value of patents (see Hall et al., 2001 and van Zeebroeck, 2011). The latter set of patent characteristics denotes the complexity of inventions and includes: the number of citations made to prior patent $(C M P B P C)$ and non patent $(C M P \perp N P C)$ documents (about 4.5 and 1 on average respectively), the number of inventors who contributed to the creation of the invention (CMP INV, 2.33 on average) and the number of IPC classes at four digits (CMP_IPC4) associated with the application 
(about 1.5 on average). The evolution of these variables is depicted in Figure A5 in the appendix, suggesting that the complexity of applications has significantly increased over time.

The last group of explanatory variables allows to account for the ownership structure (co-application, APP_MULTIPLE), and cross-border ownership (APP_CBOWN) as defined by Guellec and van Pottelsberghe (2000), and the size of the applicant's portfolio as measured with the cumulated number of applications filed to the EPO by the same applicant over the past 5 years and the current year (APP_CUMUL), under deduction of the filing considered (see van Zeebroeck et al., 2009). In case the size of the applicant portfolio is zero, the applicant can be considered as a very inexperienced patentee and an additional dummy variable (APP_OCCAS) takes the value 1 , which is the case with about $17 \%$ of EPO applications.

In addition to these variables, three sets of dummy control variables will also be included in multivariate estimates, reflecting the origin (country of residence of applicants), sector (EPO Joint Clusters; see Archontopoulos et al., 2007) and age (year of filing) of each application. Summary statistics of these control variables are reported in Table A1 in appendix.

\section{Empirical Implementation}

In order to estimate the determinants of patent length, the econometric model needs to account for the right truncation of the data, which affects some $34 \%$ of the observations in the dataset. Therefore the most appropriate option consists in survival time models. The aim of these models is to estimate the time to a certain event (called a 'failure'). In our case, a failure occurs when the patent application or grant exits the patent system and falls into the public domain.

To model patent length, one needs to estimate the survival, failure or hazard functions. The duration of a patent is a realization of a random variable $T$ with a given cumulative distribution function $F(t)$ and probability density function $f(t)$. In the duration analysis literature, $F(t)$ is frequently denoted as the failure function and is defined as $F(t)=\operatorname{Pr}(T \leq t)$, that is the probability that the patent died before or at time $t$. The survival function, denoted $S(t)$ where $t$ is the elapsed time since the patent was filed, can be computed as $S(t)=\operatorname{Pr}(T>t)=1-F(t)$. Since it represents probabilities, the survival function lies between zero and one and is a strictly decreasing function of $t$ (Jenkins, 2005) 9 It follows that

$$
f(t)=\lim _{\Delta t \rightarrow 0} \frac{\operatorname{Pr}(t \leq T \leq t+\Delta t)}{\Delta t}=\frac{\partial F(t)}{\partial t}=-\frac{\partial S(t)}{\partial t} .
$$

The hazard rate, $\theta(t)$, is defined as

\footnotetext{
${ }^{9}$ Note that as we observe in days (at the one day margin) periods which are actually several years long, it seems fairly reasonable to assimilate our data to continuous time data.
} 


\section{Figure 3 - Estimates of the Survival and Hazard Functions (Entire Life)}

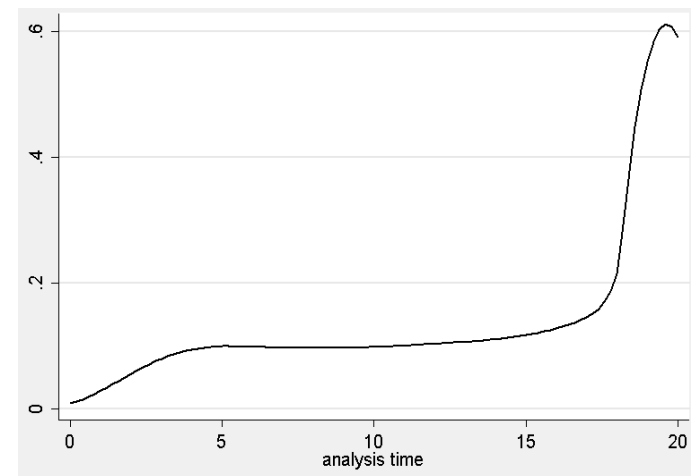

Smoothed Estimate of the Hazard Function

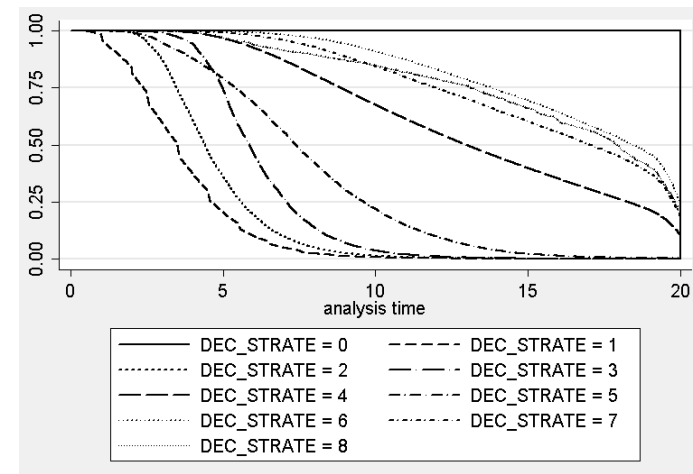

Kaplan-Meier Estimate of the Survival Function by Status $\left.{ }^{*}\right)$

$\left({ }^{*}\right)$ Legend: $0=$ Pending, $1=$ Withdrawn or Deemed withdrawn, 2=Refused, 3=Granted but lapsed ab initio, $4=$ Granted and validated but not opposed, 5=Revoked in opposition, $6=$ Amended in opposition, 7=Maintained in opposition, 8=Opposition still pending

$$
\theta(t)=\lim _{\Delta t \rightarrow 0} \frac{\operatorname{Pr}(t \leq T \leq t+\Delta t \mid T \geq t)}{\Delta t}=\frac{f(t)}{1-F(t)}=\frac{f(t)}{S(t)} .
$$

The objective of the following survival analysis will be to model the hazard function (the probability of observing a failure in time $t$ given the patent was still active or pending at time $t-1$ ), which may be achieved using non parametric and parametric (or semi-parametric) methods. The results of both methods are presented in what follows.

\subsection{Non Parametric Methods}

Figure 3 presents Kaplan-Meier estimates of the survival function and a smoothed estimate of the hazard function. They show that the hazard function strongly increases during the first five years of application (corresponding to the average decision lag), then remains constant until the $15^{\text {th }}$ year of activity before it dramatically (but logically) increases in the last 5 years as the statutory limit approaches.

The right chart in Figure 3 exhibits Kaplan-Meier estimates of the survival function by stratum, where each stratum corresponds to a given reason for failure. It appears that the first three strata, corresponding to the three reasons for lapse in the granting process (respectively withdrawal, refusal and lapse $a b$ initio) are almost parallel and distanced by about one year. This simply confirms that applications withdrawn disappear quicker than applications refused, which in turn disappear faster than applications granted but not validated (it takes about one year from the date of grant to observe that the application has indeed never been validated anywhere). A close and quasi-parallel stratum is made of patents granted but revoked in 
opposition. Here again, given that opposition proceedings last for 2 years on average, it is quite logical that these patents tend to live slightly longer than patents merely lapsed $a b$ initio.

What is more interesting to observe is the parallelism between the three next stratum, comprising patents granted and validated but never opposed and patents opposed which were either maintained or amended in opposition. It suggests that patents that survived an opposition tend to live longer than unopposed patents, and that patents amended in opposition tend to survive even longer than patents maintained as such. This result - anticipated in van Zeebroeck (2007) - would deserve further investigation in the future. Finally, the last stratum made of pending opposition cases seems to cross the stratum of patents maintained in opposition, but its twice truncated nature (patents are still active and the outcome of the opposition is itself truncated) and the low number of cases it represents makes it difficult to interpret.

Such non parametric methods can also be used to investigate potential determinants of patent length by stratifying the estimates according to categorical variables ${ }^{10}$

\subsection{Semi-parametric analysis}

Given the difficulty to determine ex ante the form of the hazard function, a semi-parametric approach will be used in the form of a Cox proportional hazard model. This model allows the relationship between the hazard rate and explanatory variables to be estimated without having to make any assumptions about the shape of the baseline hazard function (Jenkins, 2005). It makes use of a partial instead of a maximum likelihood estimation method, starting with the classical proportional hazard specification provided in Equation 3, where $\theta\left(t, X_{i}\right)$ is the hazard function, $X_{i}$ is the vector of explanatory variables, and $\beta$ is the vector of slope coefficients to be estimated:

$$
\theta\left(t, X_{i}\right)=\theta_{0}(t) \exp \left(\beta^{\prime} X_{i}\right)
$$

which reduces to an easily estimated linear model:

$$
\ln \frac{\theta\left(t, X_{i}\right)}{\theta_{0}(t)}=\beta^{\prime} X_{i}
$$

Cox (1972) proposed a method to estimate $\beta$ without needing to specify the functional form of the baseline hazard function, $\theta_{0}(t)$, which represents the individual heterogeneity. Contrary to the maximum likelihood estimators, which rely on spells, the partial likelihood used by Cox works in terms of the ordering of events. The Cox model nonetheless relies on two main assumptions: the proportional hazard assumption, which states that any absolute

\footnotetext{
${ }^{10}$ Continuous variables need to be made categorical to apply to this technique.
} 
difference in $X$ implies a proportionate difference in the hazard at each $t$, and the log-linearity of the relationship between the hazard function and the covariates. The sustainability of these assumptions will be discussed later 11

Different constructions of the estimates can be implemented, from a simple OLS regression (not accounting for the right truncation issue) of the age (in days) lived by each application to get a broad overview of the explanatory power of each potential determinant, to a Cox regression. Unstratified, the Cox model implies that both the baseline hazard function and the coefficients are to be the same no matter the reason why the patent disappeared. However, the Kaplan-Meier estimates presented in Figure 3 have shown that this assumption is not realistic as the survival functions are quite different across stratum, though fairly parallel. Therefore, estimates of the hazard function should rather be stratified by reason for patent lapse. By doing so, the model lets each stratum have a specific baseline hazard function $\left(\theta_{0}(t)\right)$, but still requires the coefficients to be the same across stratum.

\section{Empirical Results}

Kaplan-Meier estimates of the survival function stratified by categorical variables are presented in Figure 4. The different charts in this table exhibit estimates of the survival functions for different values of the variables presented in section $4 \sqrt{12}$ These figures suggest at first sight that there are very few differences in the survival function according to the number of claims and of equivalents, the ownership structure (multiple applicants or crossborder ownership) and the complexity (except for moderate differences according to the number of inventors). Moderate differences in hazard rates appear according to the route taken (accelerated search or PCT), the number of priorities (all leading to slightly greater longevities), and patent applications filed by inexperienced patentees seem to have lower life expectancies than those filed by owners of larger portfolios. Very large differences show up with four factors: divisional filings and their parents tend to live much longer than regular applications. This is also the case with triadic patents and the number of citations. The two latter results are consistent with most of the literature on patent value (see van Zeebroeck and van Pottelsberghe, 2011b).

Note that in most cases the survival functions across strata are fairly parallel, suggesting that the proportional hazard assumption underlying the econometric model presented below does not seem unreasonable in most

\footnotetext{
${ }^{11}$ However, one potential drawback in the model is the possibility that several observations share the same survival time. Given that it is measured in days for such long periods, this issue of tied outcomes should be very limited, but the model nevertheless needs to account for this possibility. This is done thanks to Breslow's partial likelihood adjustment.

${ }^{12}$ Continuous variables are categorised by their quartiles for that purpose.
} 
Figure 4 - Estimates of The Survival Function (Entire Life) by Categorical Variables
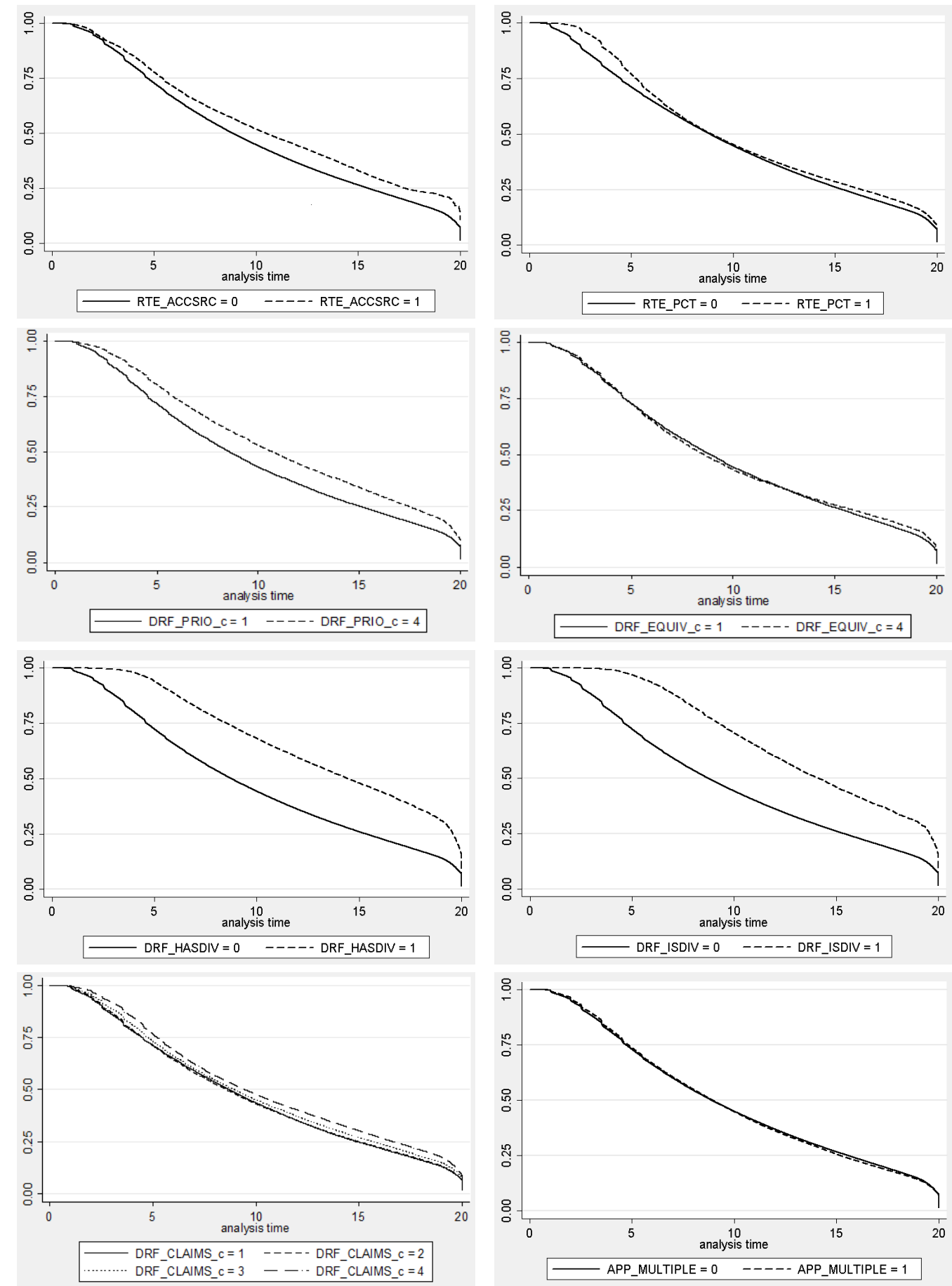
Figure 4 - (continued)
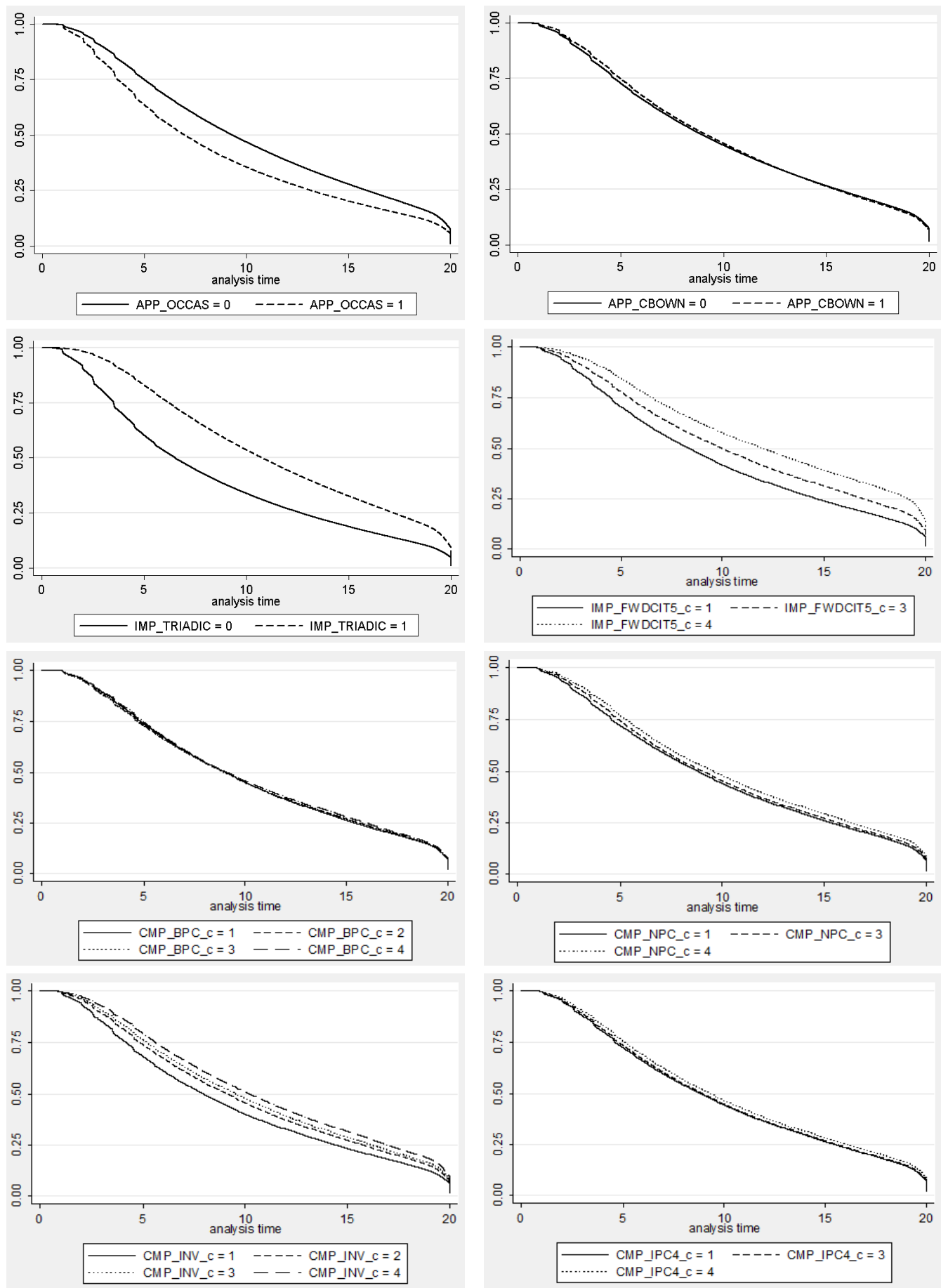
cases. This question will be investigated in more details later.

Finally, a log-rank test for trend in the survival function, aimed at testing the equality across strata and for the order of the strata in case of significant differences, does not allow the rejection of the null hypotheses of significant differences in the survival function across filing years $\left(\mathrm{Chi}^{2}(20)=10773.05\right)$ and of an increasing order in survival functions over time $\left(\mathrm{Chi}^{2}(1)=346.83\right)$. This confirms that the life expectancy of patents has increased significantly in the eighties and the nineties, or that patents have an increasing propensity to live longer.

Turning to multivariate regressions, the results of the main econometric estimates are summarised in Table 4. Different constructions of the estimates have been implemented which are detailed in this table. The first column presents the results of a simple OLS regression of the age (in days) lived by each application to get a broad overview of the explanatory power of each potential determinant. The estimated coefficients can be interpreted here as contributions of each variable to the number of days lived. The second column reports the result of a tobit-like regression, namely from a censored normal regression, possibly less sensitive to right-truncation. The third column reports a non-stratified Cox regression, while the stratified model is reported in column $4 .{ }^{13}$ In this latter column, the estimated coefficients may be interpreted as contributions to the rate of hazard, which means that a negative coefficient induces a proportional decrease in the hazard rate, that is, a higher probability of patent survival. Therefore, a significant negative coefficient suggests that the covariate increases the probability for a patent to survive longer. The stratified estimates of the Cox model strongly in line with OLS and truncated normal estimates - first show that all potential determinants included in the model are significant and that most of them have a positive effect on the length of patents. In particular, the dummy variable identifying triadic applications (IMP_TRIADIC) is associated with a very significant reduction in the hazard rate and four variables are associated with very significant parameters as well: the PCT route, forward citations received, and divisional filings - much more than their parents - are associated with very significant reductions in the hazard rate. Except the number of priorities and the dummy identifying multiple applicants, all covariates are associated with significant coefficients, and only the portfolio size (APP_CUMUL) and the dummy identifying inexperienced patentee (APP_OCCAS) are associated with an increased hazard ratio.

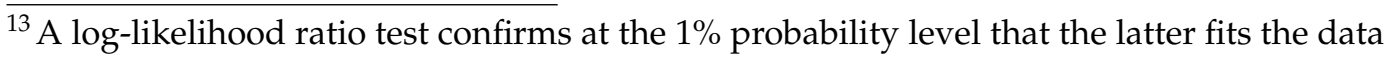
better than the unstratified model. Therefore all remaining estimates will be stratified.
} 


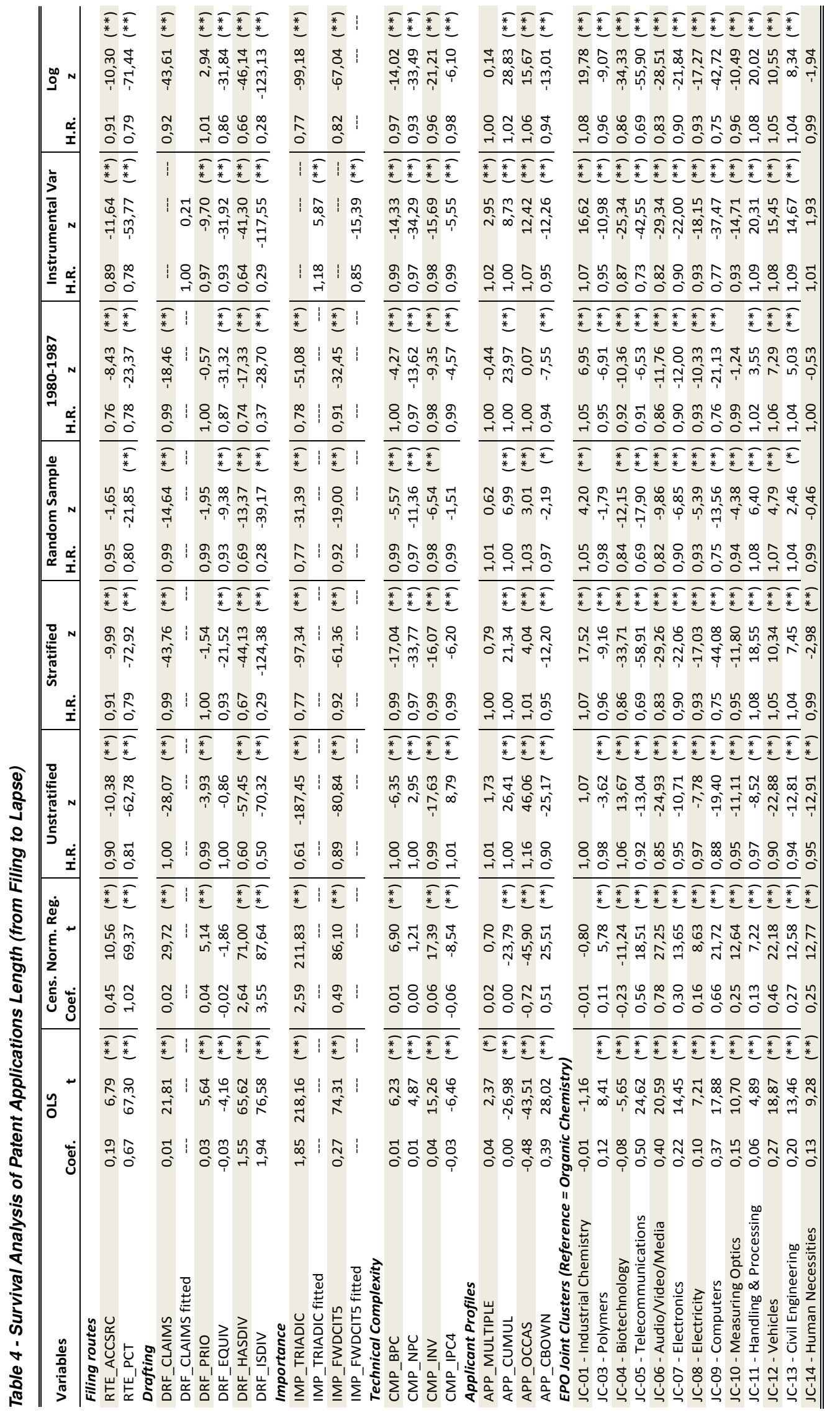




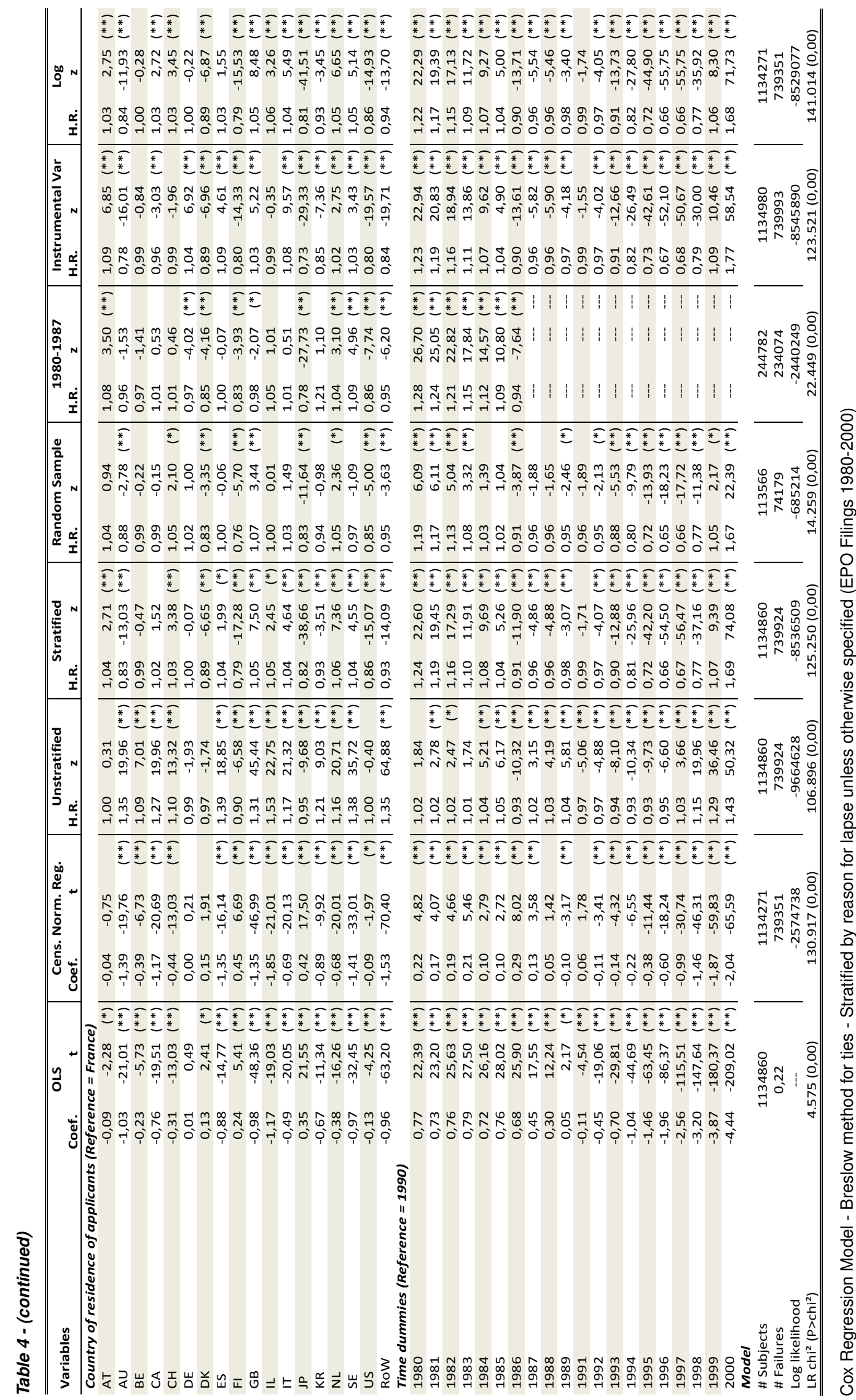


To take a closer look at the different sets of covariates is nonetheless worth the effort: it shows that both route options are associated with higher survival rates overall. This may sound logical for the PCT dummy as the international route is institutionally longer, but it is more surprising for the request of accelerated search as it should by nature result in a contraction of the decision lag. Therefore, the only explanation would be that it is associated with patents which have a higher expectancy of being either granted or renewed, or both.

Drafting variables are more mitigated: the number of claims and EP equivalents, divisional filings and their parents are associated with higher survival rates, but the number of priorities, positively associated with most value indicators according to van Zeebroeck and van Pottelsberghe (2011a), is not significant here.

Both value indicators - as already mentioned - are clearly associated with lower hazard rates. This brings at last strong support for the widely accepted idea that more valuable or more important patents do live longer overall. The complexity indicators are all associated with higher rates of survival as well. This suggests that more complex patents also tend to live longer.

Finally, applicant profiles provide additional interesting results: whereas multiple applicants have no significant effect on the hazard rate - a confirmation of what was suggested by Kaplan-Meier estimates presented in Figure 4 -, portfolio sizes seem to increase the rate of hazard, suggesting that patents filed by very small and very large applicants tend to live shorter lives than those filed by more average applicants, and the cross-border ownership of patent rights is associated with longer patents as well. This last result might have been expected since Guellec and van Pottelsberghe (2000, 2002) showed that this variable is associated with higher likelihood to be granted and given that granted patents, de facto, live longer than non granted ones.

In terms of sectors and countries, significant discrepancies appear as well: patents in the telecommunications and computers sectors survive much longer, whereas patents in industrial chemistry, handling and processing and vehicles live slightly shorter lives than average. Similarly, US, Australian, Japanese and Scandinavian patents tend to live longer than average, while UK and Dutch patents live shorter lives.

Note also that looking at the coefficients associated with time dummies, a quasi linear relationship appears, so that the hazard rate decreases more and more as years of filing increase, up to 1997 when the effect of truncation probably cancels higher life expectancies. This result reinforces the loglikelihood ratio test for trend in the survival function presented above, and clearly establishes that patents have an increasing propensity to live longer. This does however not elucidate whether this propensity actually comes from longer decision lags, from higher grant rates, from longer renewals, or 
from all of these factors.

\section{Robustness estimates}

A series of additional estimates have been run to assess the reliability of the main results presented above. First, a competing risks model - allowing the coefficients to vary across stratum - has been estimated, the results of which are reported in Table A2 in appendix. Generally speaking, most coefficients appear largely stable across the first three strata (pre-validation lapses) and between validated and opposed patents. A few variables such as the PCT dummy and applicant profiles appear however as affecting differently the hazard rates for early lapses (pre-grant) and post-grant lapses. This suggests that there may be some specific patterns in the influence of these variables on the examination process and on the renewal rate of validated patents, an idea that would deserve further investigation in the future.

Second, a test of Schoenfeld residuals - reported in Table A3 in appendix - indicates that the PH assumption might be violated on the overall model and more specifically with 10 variables (at the 3\% probability threshold). ${ }^{14}$ Therefore, a Cox model with time-varying covariates has been estimated as well - though on a random $10 \%$ sample for computational reasons. ${ }^{15}$ These estimates are reported in Table A4 in appendix. In all cases, it seems that the fixed-effect coefficient outweighs the time-varying coefficient so that the overall effect of each covariate remains negative on the hazard rate. It nevertheless suggests that these covariates decrease the hazard rate more sharply in the early ages of patents than in long survival times, possibly because they expand decision lags more than renewal rates, reinforcing the need to better investigate this issue in further research.

Third, the major issue of right truncation on the data, deserves further attention. To comfort our results, the same model has been run on a smaller sample excluding observations filed after 1987 (when the effect of truncation appears). By doing so, we guarantee, that no truncated observations should be present in the data, but this restricts the analysis to a period when the filing strategies we are analysing were only starting to appear (the PCT option, for instance, only became popular in the late eighties). The results reported in the $6^{\text {th }}$ column of Table 4 - seem globally in line with our main estimates, despite a few variations in the magnitude of the hazard ratios

\footnotetext{
${ }^{14}$ Namely: RTE_PCT,DRF_CLAIMS $, D R F \_P R I O, D R F \_E Q U I V, D R F \_H A S D I V, D R F \_I S D I V$, IMP_TRIADIC, CMP_NPC, CMP_IPC4, and APP_CBOWN.

${ }^{15} \mathrm{By}$ so doing, this provides an additional robustness test of the estimates presented in Table 4 against a 10\% random sample. Thereby comparing columns 4 and 5 in Table 4 reveals that the results are strongly stable, all covariates keeping the exact same estimated coefficient across samples, except with RTE_ACCSRC and CMP_IPC4, which were the least significant variables in the original estimates and lost most of their explanatory power with the reduced sample
} 
with some filing strategy variables, probably due to their lower exploitation in the sub-period considered (accelerated search requests, equivalents, and divisional variables). In addition, a tobit-like model (censored normal regression) reported in Table 4 as well appears very strongly in line with the preceding results.

Finally, additional robustness estimates include pooled regressions with one set of covariates at a time, ${ }^{16}$ clustered regressions by type of applicant, ${ }^{17}$ a full model where all discrete variables are taken in logarithm to reduce any potential issue with influential outliers, ${ }^{18}$ instrumental variables regressions to address some potential endogeneity issues with the 'importance' indicators. The results of all those estimates largely confirm the robustness of our main results to the sample and the model specification.

\section{Concluding Remarks}

The objective of this paper was to investigate the evolution and explore the determinants of patent length. Its main originality resides in three elements: first it takes into account the entire life of patent applications from filing to lapse, no matter they were granted a patent or not; second it covers all applications filed to the EPO over a 20 years period; and third it explores the impact of a wide range of potential determinants on the duration of patent rights in Europe. Three main messages may be drawn from this exercise.

First of all, the present paper clearly establishes that the length of patent rights in Europe has significantly increased over the eighties and the nineties despite an apparent (but slow) decline in the average grant rate. This increase may be due to the dilatation of the examination process (significant increase in decision lags), or to higher maintenance rates (significant increase in patent renewals), or both. More work would be needed to disentangle these potential factors, but they readily suggest that monopolistic rents may be extracted over longer periods by patent holders, with unknown consequences on the dynamic efficiency of patents.

Second, these developments were not even across technology fields. In particular, our results suggest that emerging technologies, which also make the most controversial subject matter in today's patent system (i.e. biotechnologies, computers and telecommunications), are associated with the longest patent rights. This may be due to evolving patenting standards in these technological fields, resulting in a smaller predictability of the patentability requirements and hence more complexity in the examination, but also to specificities in competitive processes on these markets that induce a partic-

\footnotetext{
${ }^{16}$ See Table A5 in appendix.

${ }^{17}$ See Table A6 in appendix.

${ }^{18}$ See the last column of Table 4 .
} 
ular focus onto IP rights. 19

Third, it clearly appears that most filing strategies are associated with longer patent rights, but it appears that they may affect the length of patents slightly differently before and after grant, i.e. they may have different impacts on the duration of the examination process and on renewal rates. In particular, although increasingly popular, the filing of divisionals remains an exceptional practice (about $4.5 \%$ of applications filed in the late nineties were divisionals), but this practice seems to have a major impact on the length of patents. This is of great importance, because such strategies are in fact procedures allowed by the European Patent Convention that are actionable by firms, for instance when they deem it in their interest to delay the grant decision on their patents, at the expense of a greater legal uncertainty on the markets.

These results therefore suggest that the exclusive rights offered by patents tend to be exploited by the patentees over longer periods, but that this is not only a matter of patents being more important and valuable and therefore renewed for longer periods after grant, but it is largely a matter of filing strategies used by firms with effect to delay the grant decision on their patents. It is hard to imagine why such a growing uncertainty on the markets would be beneficial to competition, to the functioning of technology markets, and to society at large. Still, further research would be greatly needed to disentangle the influence of filing strategies on the granting process and on grant and renewal rates and to better understand the motivations of the firms who rely on such strategies.

\footnotetext{
${ }^{19}$ This speculation is consistent with the hypothesis - tested in van Zeebroeck et al. (2009) - that these sectors are characterised by a less established vocabulary, resulting in larger patent applications.
} 


\section{References}

Archontopoulos, E., Guellec, D., Stevnsborg, N., van Pottelsberghe de la Potterie, B., \& van Zeebroeck, N. (2007). When Small is Beautiful: Measuring the Evolution and Consequences of the Voluminosity of Patent Applications at the EPO. Information Economics and Policy, 19(2), 103-132. doi:10.1016/j.infoecopol.2007.01.001

Bessen, J. (2008). The Value of U.S. Patents by Owner and Patent Characteristics. Research Policy, 37(5), 932-945.

Cornelli, F., \& Schankerman, M. (1999). Patent Renewals and R\&D Incentives. The RAND Journal of Economics, 30(2), 197-213.

Cox, D. (1972). Regression Models and Life Tables. Journal of Royal Statistical Society, 34(2), 187-220.

Deng, Y. (2005). Renewal Study of European Patents: a Three-country Comparison. (Department of Economics Working Papers n. 0514). Southern Methodist University. http://econpapers.repec.org/RePEc:smu:ecowpa:0514

EPO (2006). EPO Worldwide Patent Statistical Database. European Patent Office.

Gilbert, R., \& Shapiro, C. (1990). Optimal Patent Length and Breadth. The RAND Journal of Economics, 21(1), 106-112.

Guellec, D., \& van Pottelsberghe de la Potterie, B. (2000). Applications, Grants and the Value of Patent. Economic Letters, 69(1), 109-114. doi:10.1016/S0165-1765(00)00265-2

Guellec, D., \& van Pottelsberghe de la Potterie, B. (2002). The Value of Patents and Filing Strategies: Countries and Technology Areas Patterns. Economics of Innovation and New Technology, 11(2), 133-148. doi:10.1080/10438590210896

Guellec, D., \& van Pottelsberghe de la Potterie, B. (2007). The Economics of the European Patent System. Oxford: Oxford University Press.

Hall, B., Jaffe, A., \& Trajtenberg, M. (2001). The NBER Patent Citations Data File: Lessons, Insights and Methodological Tools. (NBER Working Paper No. 8498). Retrieved from Nationl Bureau of Economic Research website: http://www.nber.org/papers/w8498.pdf

Harhoff, D. (2006). "Patent Constructionism: Exploring the Microstructure of Patent Portfolios". Presentation Prepared for the EPO/OECD Conference on Patent Statistics for Policy Decision Making, Vienna, October 23-24. 
Harhoff, D., \& Wagner, S. (2009). The Duration of Patent Examination at the European Patent Office. Management Science, 55(12), 1969-1984.

Jaffe, A., \& Lerner, J. (2004). Innovation and Its Discontents. Princeton: Princeton University Press.

Jenkins, S. (2005). Survival Analysis. Unpublished manuscript. Institute for Social and Economic Research, University of Essex, Colchester, UK.

Kortum, S., \& Lerner, J. (1999). What Is Behind the Recent Surge in Patenting. Research Policy, 28(1), 1-22. doi:10.1016/S0048-7333(98)00082-1

Lanjouw, J., Pakes, A., \& Putnam, J. (1998). How to Count Patents and Value Intellectual Property: the Uses of Patent Renewal and Application Data. The Journal of Industrial Economics, 46(4), 405-432. doi:10.1111/14676451.00081

Maurseth, P. (2005). Lovely but Dangerous: the Impact of Patent Citations on Patent Renewal. Economics of Innovation and New Technology, 14(5), 35174. doi:10.1080/1043859042000307338

Minoo, P. (2006). Patent Filing and Searching: is Deflation in Quality the Inevitable Consequence of Hyperinflation in Quantity?. World Patent Information, 28(2), 117-121. doi:10.1016/j.wpi.2006.01.006

O'Donoghue, T., Scotchmer, S., \& Thisse, J.F. (1998). Patent Breadth, Patent Life, and the Pace of Technological Progress. Journal of Economics EManagement Strategy, 7(1), 1-32.

OECD (2004). Triadic Patent Families Dataset.

Pakes, A. (1986). Patents as Options: Some Estimates of the Value of Holding European Patent Stocks. Econometrica, 54(4), 755-784.

Pakes, A., \& Schankerman, M. (1984). The Rate of Obsolescence Of Knowledge, Research Gestation Lags, and the Private Rate of Return to Research Resources. (NBER Working Paper No. 0346). Retrieved from National Bureau of Economic Research website: http://www.nber.org/papers/w0346.pdf

Pakes, A., \& Simpson, M. (1989). Patent Renewal Data, Brookings Papers on Economic Activity. Microeconomics, 1989, 331-401.

Popp, D., Juhl, T., \& Johnson, D., (2004). Time in Purgatory: Determinants of the Grant Lag for US Patent Applications. Topics in Economic Analysis \& Policy, 4(1), Article 29. Available at: http://www.bepress.com/bejeap/topics/vol4/iss1/art29. 
Putnam, J. (1996). The Value of International Patent Rights. Connecticut, NJ: Yale University Press.

Regibeau, P., \& Rockett, K. (2003). Are More Important Patents Approved more Slowly and Should They be? Department of Economics Working Paper No. 556. University of Essex.

Schankerman, M. (1998). How Valuable is Patent Protection? Estimates by Technology Field. The RAND Journal of Economics, 29(1), 77-107.

Schankerman, M., \& Pakes, A. (1986). Estimates of the Value of Patent Rights in European Countries During the Post-1950 Period. The Economic Journal, 96(384), 1052-1076. doi:10.2307/2233173

Scotchmer, S. (1999). On the Optimality of the Patent Renewal System. The RAND Journal of Economics, 30(2), 181-196.

Stevnsborg, N., \& van Pottelsberghe de la Potterie, B. (2007). Patenting Procedures and Filing Strategies. In Guellec, D., van Pottelsberghe de la Potterie, B. (Eds.). The Economics of the European Patent System (pp.155-183). Oxford: Oxford University Press.

Svensson, R. (2007). Licensing or Acquiring Patents? Evidence from Patent Renewal Data. Paper presented at the EEA-ESEM Conference, Budapest, August 2007.

van Pottelsberghe de la Potterie, B., \& François, D. (2009). The Cost Factor in Patent Systems. Journal of industry, competition and trade, 9(4), 329-355. doi:10.1007/s10842-008-0033-2

van Pottelsberghe de la Potterie, B., \& van Zeebroeck, N. (2008). A Brief History of Space and Time: the Scope-Year Index as a Patent Value Indicator Based on Families and Renewals. Scientometrics, 75(2), 319-338. doi:10.1007/s11192-007-1864-z

van Zeebroeck, N. (2007). Patents Only Live Twice: a Patent Survival Analysis in Europe. CEB Working Paper 07-028.

van Zeebroeck, N., \& van Pottelsberghe de la Potterie, B. (2011a). Filing Strategies and Patent Value. Economics of Innovation and New Technology, O(0), 1-23. doi:10.1080/10438591003668646

van Zeebroeck, N., \& van Pottelsberghe de la Potterie, B. (2011b), The Vulnerability of Ppatent Value Determinants, Economics of Innovation and New Technology, 20(3), 283-308. doi:10.1080/10438591003668638

van Zeebroeck, N. (2011). The Puzzle of Patent Value Indicators. Economics of Innovation and New Technology, 20(1), 33-62. doi:10.1080/10438590903038256 
van Zeebroeck, N., van Pottelsberghe de la Potterie, B., \& Guellec, D. (2009), Claiming More: the Increased Voluminosity of Patent Applications and its Determinants. Research Policy, 38(6), 1006-1020. doi:10.1016/j.respol.2009.02.004

Yang, D. (2007). Intellectual Property System in China: A Study of the Grant Lags and Ratios. The Journal of World Intellectual Property, Vol. 10(1), 22-52. doi:10.1111/j.1422-2213.2007.00313.x 


\section{Appendix}

Table A1 - Summary Statistics of Control Variables

\begin{tabular}{|c|c|c|c|c|c|c|}
\hline Variable & 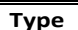 & Obs. & Mean & Std. Dev. & "Min & Max \\
\hline \multicolumn{7}{|c|}{ EPO Joint Clusters (Reference = Organic Chemistry) } \\
\hline JC-01 - Industrial Chemistry & $\mathrm{Y} / \mathrm{N}$ & 1189058 & 0.12 & 0.32 & 0.00 & 1.00 \\
\hline JC-02 - Organic Chemistry & $\mathrm{Y} / \mathrm{N}$ & 1189058 & 0.14 & 0.35 & 0.00 & 1.00 \\
\hline JC-03 - Polymers & $\mathrm{Y} / \mathrm{N}$ & 1189058 & 0.10 & 0.30 & 0.00 & 1.00 \\
\hline JC-04 - Biotechnology & $\mathrm{Y} / \mathrm{N}$ & 1189058 & 0.12 & 0.32 & 0.00 & 1.00 \\
\hline JC-05 - Telecommunications & $\mathrm{Y} / \mathrm{N}$ & 1189058 & 0.04 & 0.20 & 0.00 & 1.00 \\
\hline JC-06 - Audio/Video/Media & $\mathrm{Y} / \mathrm{N}$ & 1189058 & 0.05 & 0.21 & 0.00 & 1.00 \\
\hline JC-07 - Electronics & $\mathrm{Y} / \mathrm{N}$ & 1189058 & 0.07 & 0.26 & 0.00 & 1.00 \\
\hline JC-08 - Electricity & $\mathrm{Y} / \mathrm{N}$ & 1189058 & 0.11 & 0.31 & 0.00 & 1.00 \\
\hline JC-09-Computers & $\mathrm{Y} / \mathrm{N}$ & 1189058 & 0.04 & 0.20 & 0.00 & 1.00 \\
\hline JC-10 - Measuring Optics & $\mathrm{Y} / \mathrm{N}$ & 1189058 & 0.09 & 0.29 & 0.00 & 1.00 \\
\hline JC-11 - Handling \& Processing & $\mathrm{Y} / \mathrm{N}$ & 1189058 & 0.13 & 0.34 & 0.00 & 1.00 \\
\hline JC-12 - Vehicles & $\mathrm{Y} / \mathrm{N}$ & 1189058 & 0.10 & 0.30 & 0.00 & 1.00 \\
\hline JC-13 - Civil Engineering & $\mathrm{Y} / \mathrm{N}$ & 1189058 & 0.09 & 0.29 & 0.00 & 1.00 \\
\hline \multicolumn{7}{|c|}{ Country of residence of applicants } \\
\hline AT & $\mathrm{Y} / \mathrm{N}$ & 1189058 & 0.01 & 0.10 & 0.00 & 1.00 \\
\hline $\mathrm{AU}$ & $\mathrm{Y} / \mathrm{N}$ & 1189058 & 0.01 & 0.08 & 0.00 & 1.00 \\
\hline $\mathrm{BE}$ & $\mathrm{Y} / \mathrm{N}$ & 1189058 & 0.01 & 0.10 & 0.00 & 1.00 \\
\hline CA & $\mathrm{Y} / \mathrm{N}$ & 1189058 & 0.01 & 0.10 & 0.00 & 1.00 \\
\hline $\mathrm{CH}$ & $\mathrm{Y} / \mathrm{N}$ & 1189058 & 0.04 & 0.19 & 0.00 & 1.00 \\
\hline $\mathrm{DE}$ & $\mathrm{Y} / \mathrm{N}$ & 1189058 & 0.20 & 0.40 & 0.00 & 1.00 \\
\hline DK & $\mathrm{Y} / \mathrm{N}$ & 1189058 & 0.01 & 0.08 & 0.00 & 1.00 \\
\hline ES & $\mathrm{Y} / \mathrm{N}$ & 1189058 & 0.00 & 0.07 & 0.00 & 1.00 \\
\hline $\mathrm{FI}$ & $\mathrm{Y} / \mathrm{N}$ & 1189058 & 0.01 & 0.09 & 0.00 & 1.00 \\
\hline FR & $\mathrm{Y} / \mathrm{N}$ & 1189058 & 0.08 & 0.27 & 0.00 & 1.00 \\
\hline GB & $\mathrm{Y} / \mathrm{N}$ & 1189058 & 0.06 & 0.23 & 0.00 & 1.00 \\
\hline IL & $\mathrm{Y} / \mathrm{N}$ & 1189058 & 0.00 & 0.06 & 0.00 & 1.00 \\
\hline IT & $\mathrm{Y} / \mathrm{N}$ & 1189058 & 0.03 & 0.18 & 0.00 & 1.00 \\
\hline$J P$ & $\mathrm{Y} / \mathrm{N}$ & 1189058 & 0.17 & 0.38 & 0.00 & 1.00 \\
\hline KR & $\mathrm{Y} / \mathrm{N}$ & 1189058 & 0.00 & 0.07 & 0.00 & 1.00 \\
\hline NL & $\mathrm{Y} / \mathrm{N}$ & 1189058 & 0.04 & 0.19 & 0.00 & 1.00 \\
\hline $\mathrm{SE}$ & $\mathrm{Y} / \mathrm{N}$ & 1189058 & 0.02 & 0.14 & 0.00 & 1.00 \\
\hline US & $\mathrm{Y} / \mathrm{N}$ & 1189058 & 0.02 & 0.14 & 0.00 & 1.00 \\
\hline RoW & $\mathrm{Y} / \mathrm{N}$ & 1189058 & 0.29 & 0.46 & 0.00 & 1.00 \\
\hline \multicolumn{7}{|c|}{ Time dummies (Year of filing at EPO) } \\
\hline 1980 & $\mathrm{Y} / \mathrm{N}$ & 1189058 & 0.02 & 0.13 & 0.00 & 1.00 \\
\hline 1981 & $\mathrm{Y} / \mathrm{N}$ & 1189058 & 0.02 & 0.14 & 0.00 & 1.00 \\
\hline 1982 & $\mathrm{Y} / \mathrm{N}$ & 1189058 & 0.02 & 0.15 & 0.00 & 1.00 \\
\hline 1983 & $\mathrm{Y} / \mathrm{N}$ & 1189058 & 0.03 & 0.16 & 0.00 & 1.00 \\
\hline 1984 & $\mathrm{Y} / \mathrm{N}$ & 1189058 & 0.03 & 0.17 & 0.00 & 1.00 \\
\hline 1985 & $\mathrm{Y} / \mathrm{N}$ & 1189058 & 0.03 & 0.18 & 0.00 & 1.00 \\
\hline 1986 & $\mathrm{Y} / \mathrm{N}$ & 1189058 & 0.04 & 0.18 & 0.00 & 1.00 \\
\hline 1987 & $\mathrm{Y} / \mathrm{N}$ & 1189058 & 0.04 & 0.19 & 0.00 & 1.00 \\
\hline 1988 & $\mathrm{Y} / \mathrm{N}$ & 1189058 & 0.04 & 0.20 & 0.00 & 1.00 \\
\hline 1989 & $\mathrm{Y} / \mathrm{N}$ & 1189058 & 0.05 & 0.21 & 0.00 & 1.00 \\
\hline 1990 & $\mathrm{Y} / \mathrm{N}$ & 1189058 & 0.05 & 0.23 & 0.00 & 1.00 \\
\hline 1991 & $\mathrm{Y} / \mathrm{N}$ & 1189058 & 0.05 & 0.22 & 0.00 & 1.00 \\
\hline 1992 & $\mathrm{Y} / \mathrm{N}$ & 1189058 & 0.05 & 0.22 & 0.00 & 1.00 \\
\hline 1993 & $\mathrm{Y} / \mathrm{N}$ & 1189058 & 0.05 & 0.22 & 0.00 & 1.00 \\
\hline 1994 & $\mathrm{Y} / \mathrm{N}$ & 1189058 & 0.05 & 0.22 & 0.00 & 1.00 \\
\hline 1995 & $\mathrm{Y} / \mathrm{N}$ & 1189058 & 0.05 & 0.23 & 0.00 & 1.00 \\
\hline 1996 & $\mathrm{Y} / \mathrm{N}$ & 1189058 & 0.06 & 0.24 & 0.00 & 1.00 \\
\hline 1997 & $\mathrm{Y} / \mathrm{N}$ & 1189058 & 0.07 & 0.25 & 0.00 & 1.00 \\
\hline 1998 & $\mathrm{Y} / \mathrm{N}$ & 1189058 & 0.08 & 0.26 & 0.00 & 1.00 \\
\hline 1999 & $\mathrm{Y} / \mathrm{N}$ & 1189058 & 0.08 & 0.27 & 0.00 & 1.00 \\
\hline 2000 & $\mathrm{Y} / \mathrm{N}$ & 1189058 & 0.09 & 0.29 & 0.00 & 1.00 \\
\hline
\end{tabular}




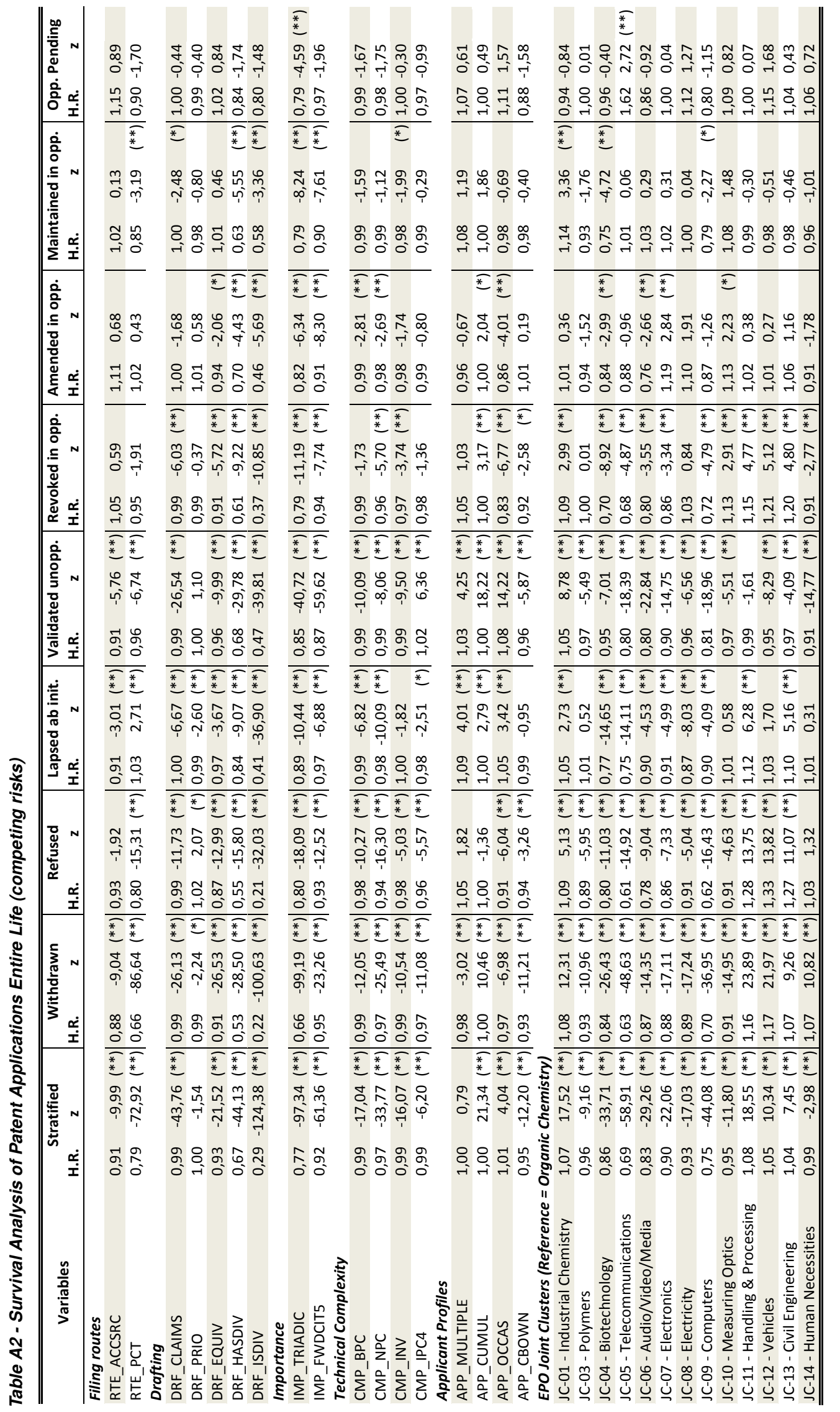




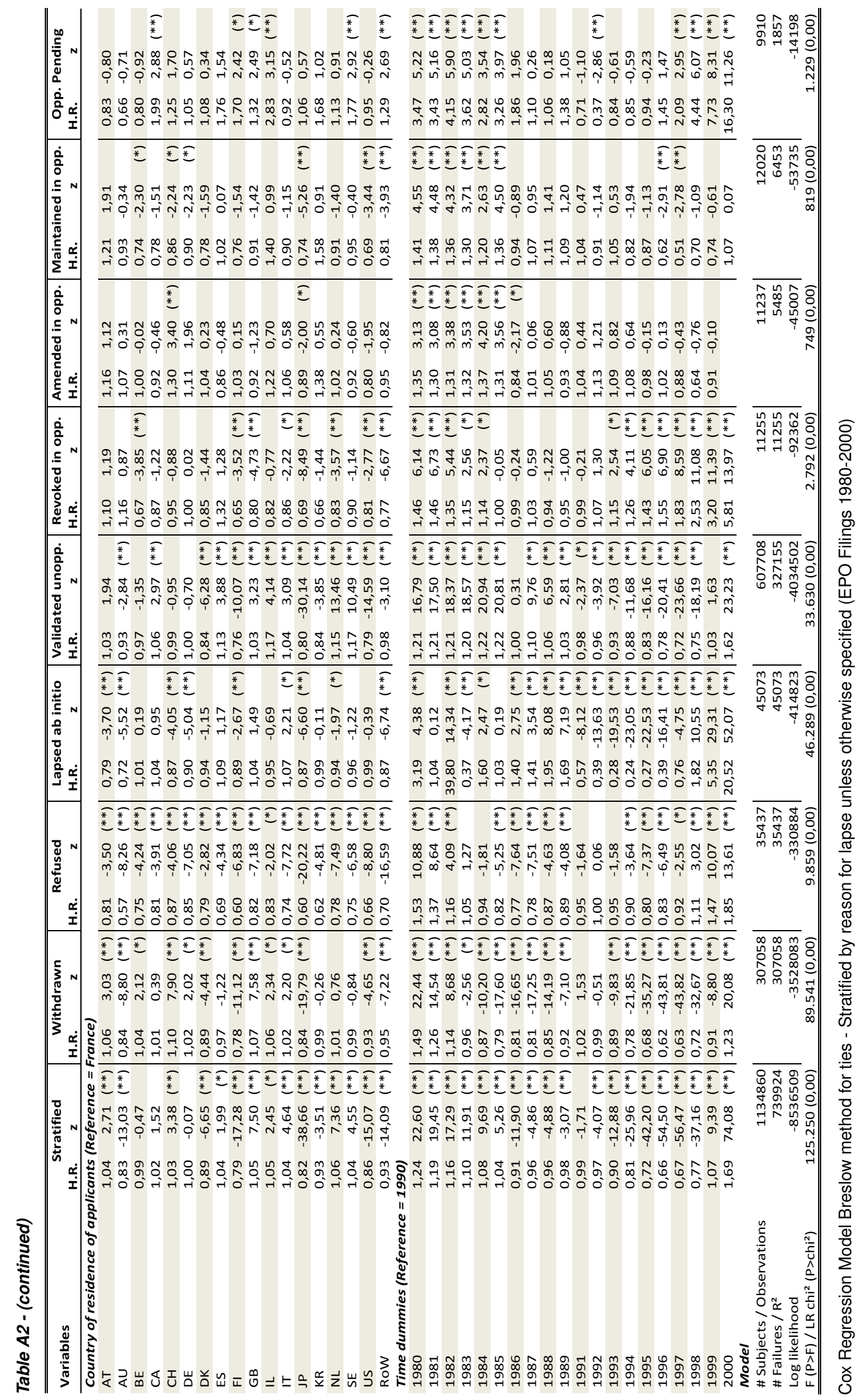


Table A3 - Test of the PH Assumption in Entire Life Model

\begin{tabular}{l|cccc}
\hline \hline & rho & chi2 & df & Prob>chi2 \\
\hline Filing routes & & & & \\
RTE_ACCSRC & 0.00 & 0.30 & 1.00 & 0.58 \\
RTE_PCT & 0.05 & 203.88 & 1.00 & 0.00 \\
Drafting & & & & \\
DRF_CLAIMS & 0.02 & 35.81 & 1.00 & 0.00 \\
DRF_PRIO & 0.01 & 8.43 & 1.00 & 0.00 \\
DRF_EQUIV & -0.01 & 4.76 & 1.00 & 0.03 \\
DRF_HASDIV & 0.02 & 19.04 & 1.00 & 0.00 \\
DRF_ISDIV & 0.06 & 227.32 & 1.00 & 0.00 \\
Importance & & & & \\
IMP_TRIADIC & 0.06 & 302.80 & 1.00 & 0.00 \\
IMP_FWDCIT5 & 0.00 & 0.14 & 1.00 & 0.70 \\
Technical Complexity & & & & \\
CMP_BPC & 0.00 & 1.29 & 1.00 & 0.26 \\
CMP_NPC & 0.01 & 14.61 & 1.00 & 0.00 \\
CMP_INV & 0.01 & 2.03 & 1.00 & 0.15 \\
CMP_IPC4 & 0.01 & 9.70 & 1.00 & 0.00 \\
Applicant Profiles & & & & \\
APP_MULTIPLE & 0.01 & 4.51 & 1.00 & 0.03 \\
APP_CUMUL & 0.00 & 0.12 & 1.00 & 0.73 \\
APP_OCCAS & 0.00 & 0.30 & 1.00 & 0.59 \\
APP_CBOWN & 0.01 & 5.77 & 1.00 & 0.02 \\
Global Test & & $\mathbf{2 6 4 6 . 8 8}$ & $\mathbf{6 8 . 0 0}$ & $\mathbf{0 . 0 0}$ \\
\hline \hline
\end{tabular}

Cox Regression Model - Breslow method for ties

Figure A1 - Evolution of EPO Patent Applications Entire Life (from filing to lapse) using the SRA approach

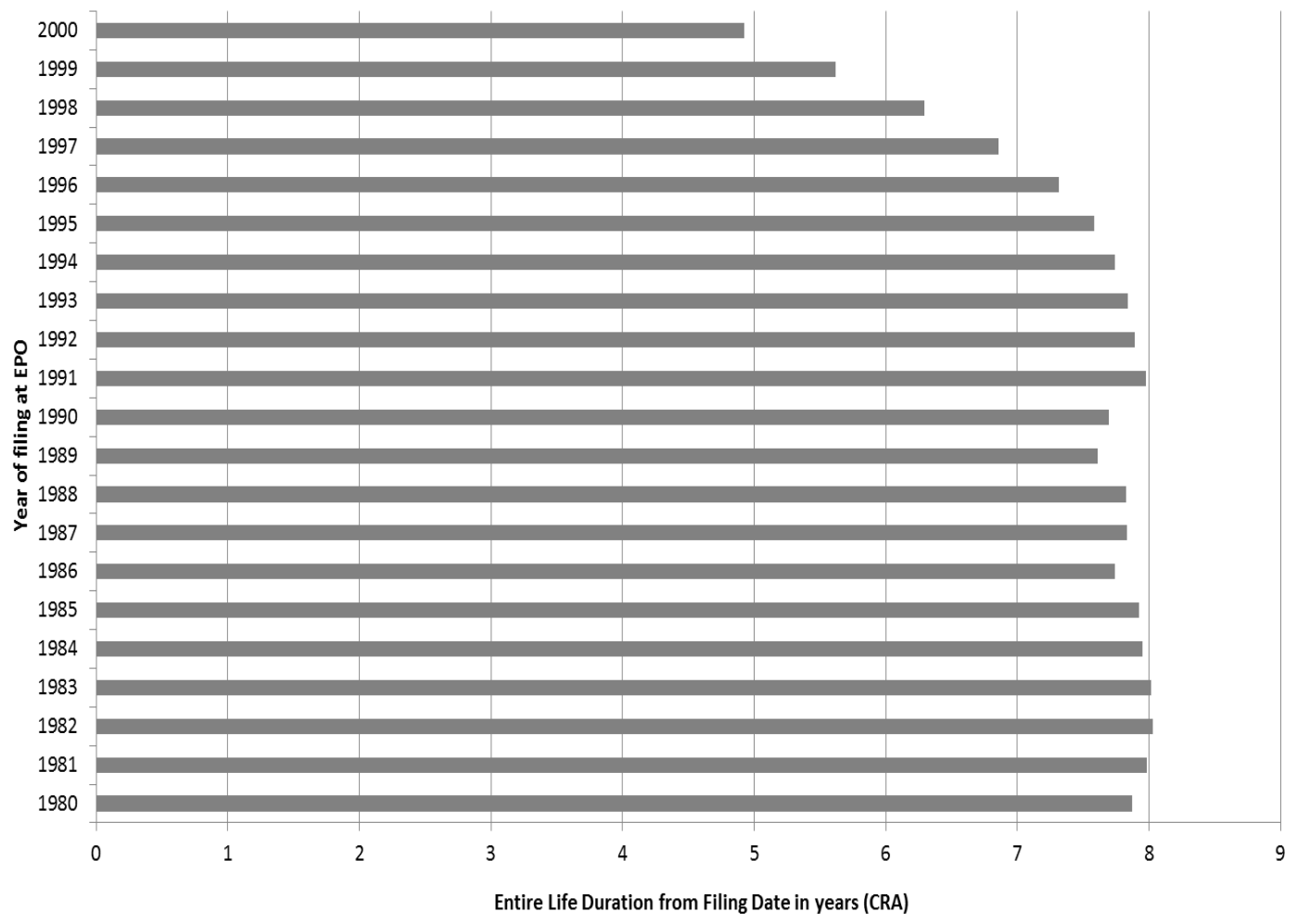


Table A4 - Survival Analysis of Patent Applications Entire Life with TVC

\begin{tabular}{|c|c|c|c|c|c|c|c|c|c|}
\hline \multirow[b]{2}{*}{ Variables } & \multicolumn{3}{|c|}{ No TVC } & \multicolumn{3}{|c|}{ No TVC Random } & \multicolumn{3}{|c|}{ TVC Stratified } \\
\hline & H.R. & $\mathbf{z}$ & & H.R. & $\mathbf{z}$ & & H.R. & $\mathbf{z}$ & \\
\hline \multicolumn{10}{|l|}{ Filing routes } \\
\hline RTE_ACCSRC & 0,91 & $-9,99$ & $(* *)$ & 0,95 & $-1,65$ & & 0,95 & $-1,70$ & \\
\hline RTE_PCT & 0,79 & $-72,92$ & $(* *)$ & 0,80 & $-21,85$ & $(* *)$ & 0,01 & $-34,96$ & $(* *)$ \\
\hline RTE_PCT * $\ln ($ t $t)$ & & & & & & & 1,73 & 33,59 & $(* *)$ \\
\hline \multicolumn{10}{|l|}{ Drafting } \\
\hline DRF_CLAIMS & 0,99 & $-43,76$ & $(* *)$ & 0,99 & $-14,64$ & $(* *)$ & 0,95 & $-10,92$ & $(* *)$ \\
\hline DRF_CLAIMS * $\ln \left(\_t\right)$ & & & & & & & 1,01 & 9,83 & $(* *)$ \\
\hline DRF_PRIO & 1,00 & $-1,54$ & & 0,99 & $-1,95$ & & 0,86 & $-2,60$ & $(* *)$ \\
\hline DRF_PRIO * $\ln ($ t $)$ & & & & & & & 1,02 & 2,43 & $(*)$ \\
\hline DRF_EQUIV & 0,93 & $-21,52$ & $(* *)$ & 0,93 & $-9,38$ & $(* *)$ & 1,25 & 2,55 & $(*)$ \\
\hline DRF_EQUIV * $\ln ($ _t $)$ & & & & & & & 0,96 & $-3,30$ & $(* *)$ \\
\hline DRF_HASDIV & 0,67 & $-44,13$ & $(* *)$ & 0,69 & $-13,37$ & $(* *)$ & 0,08 & $-5,45$ & $(* *)$ \\
\hline DRF_HASDIV * $\ln (\mathrm{t})$ & & & & & & & 1,30 & 4,58 & $(* *)$ \\
\hline DRF_ISDIV & 0,29 & $-124,38$ & $(* *)$ & 0,28 & $-39,17$ & $(* *)$ & 0,00 & $-18,90$ & $(* *)$ \\
\hline DRF_ISDIV * $\ln ($ _t $)$ & & & & & & & 3,53 & 17,13 & $(* *)$ \\
\hline \multicolumn{10}{|l|}{ Importance } \\
\hline IMP_TRIADIC & 0,77 & $-97,34$ & $(* *)$ & 0,77 & $-31,39$ & $(* *)$ & 0,07 & $-28,25$ & $(* *)$ \\
\hline IMP_TRIADIC * In(_t) & & & & & & & 1,38 & 25,61 & $(* *)$ \\
\hline IMP_FWDCIT5 & 0,92 & $-61,36$ & $(* *)$ & 0,92 & $-19,00$ & $(* *)$ & 0,91 & $-20,69$ & $(* *)$ \\
\hline \multicolumn{10}{|l|}{ Technical Complexity } \\
\hline CMP_BPC & 0,99 & $-17,04$ & $(* *)$ & 0,99 & $-5,57$ & $(* *)$ & 0,99 & $-5,64$ & $(* *)$ \\
\hline CMP_NPC & 0,97 & $-33,77$ & $(* *)$ & 0,97 & $-11,36$ & $(* *)$ & 0,74 & $-10,06$ & $(* *)$ \\
\hline CMP_NPC * $\ln ($ _t $)$ & & & & & & & 1,04 & 9,18 & $(* *)$ \\
\hline CMP_INV & 0,99 & $-16,07$ & $(* *)$ & 0,98 & $-6,54$ & $(* *)$ & 0,98 & $-6,20$ & $(* *)$ \\
\hline CMP_IPC4 & 0,99 & $-6,20$ & $(* *)$ & 0,99 & $-1,51$ & & 0,97 & $-0,61$ & \\
\hline CMP_IPC4 * In(_t) & & & & & & & 1,00 & 0,47 & \\
\hline \multicolumn{10}{|l|}{ Applicant Profiles } \\
\hline APP_MULTIPLE & 1,00 & 0,79 & & 1,01 & 0,62 & & 1,02 & 1,16 & \\
\hline APP_CUMUL & 1,00 & 21,34 & $(* *)$ & 1,00 & 6,99 & $(* *)$ & 1,00 & 7,03 & $(* *)$ \\
\hline APP_OCCAS & 1,01 & 4,04 & $(* *)$ & 1,03 & 3,01 & $(* *)$ & 1,01 & 1,38 & \\
\hline APP_CBOWN & 0,95 & $-12,20$ & $(* *)$ & 0,97 & $-2,19$ & $(*)$ & 0,50 & $-4,70$ & $(* *)$ \\
\hline APP_CBOWN * $\ln \left(\_t\right)$ & & & & & & & 1,09 & 4,48 & $(* *)$ \\
\hline \multicolumn{10}{|c|}{ EPO Joint Clusters (Reference = Organic Chemistry) } \\
\hline JC-01 - Industrial Chemistry & 1,07 & 17,52 & $(* *)$ & 1,05 & 4,20 & $(* *)$ & 1,05 & 3,81 & $(* *)$ \\
\hline JC-03 - Polymers & 0,96 & $-9,16$ & $(* *)$ & 0,98 & $-1,79$ & & 0,97 & $-2,04$ & $(*)$ \\
\hline JC-04 - Biotechnology & 0,86 & $-33,71$ & $(* *)$ & 0,84 & $-12,15$ & $(* *)$ & 0,85 & $-11,67$ & $(* *)$ \\
\hline JC-05 - Telecommunications & 0,69 & $-58,91$ & $(* *)$ & 0,69 & $-17,90$ & $(* *)$ & 0,68 & $-18,22$ & $(* *)$ \\
\hline JC-06 - Audio/Video/Media & 0,83 & $-29,26$ & $(* *)$ & 0,82 & $-9,86$ & $(* *)$ & 0,82 & $-9,97$ & $(* *)$ \\
\hline JC-07 - Electronics & 0,90 & $-22,06$ & $(* *)$ & 0,90 & $-6,85$ & $(* *)$ & 0,90 & $-7,31$ & $(* *)$ \\
\hline JC-08 - Electricity & 0,93 & $-17,03$ & $(* *)$ & 0,93 & $-5,39$ & $(* *)$ & 0,93 & $-5,35$ & $(* *)$ \\
\hline JC-09 - Computers & 0,75 & $-44,08$ & $(* *)$ & 0,75 & $-13,56$ & $(* *)$ & 0,75 & $-13,75$ & $(* *)$ \\
\hline JC-10 - Measuring Optics & 0,95 & $-11,80$ & $(* *)$ & 0,94 & $-4,38$ & $(* *)$ & 0,93 & $-5,04$ & $(* *)$ \\
\hline JC-11 - Handling \& Processing & 1,08 & 18,55 & $(* *)$ & 1,08 & 6,40 & $(* *)$ & 1,08 & 5,87 & $(* *)$ \\
\hline JC-12 - Vehicles & 1,05 & 10,34 & $(* *)$ & 1,07 & 4,79 & $(* *)$ & 1,07 & 4,57 & $(* *)$ \\
\hline JC-13 - Civil Engineering & 1,04 & 7,45 & $(* *)$ & 1,04 & 2,46 & $(*)$ & 1,03 & 1,93 & \\
\hline JC-14 - Human Necessities & 0,99 & $-2,98$ & $(* *)$ & 0,99 & $-0,46$ & & 0,99 & $-0,81$ & \\
\hline
\end{tabular}


Table A4 - (continued)

\begin{tabular}{|c|c|c|c|c|c|c|c|c|c|}
\hline \multirow{2}{*}{ Variables } & \multicolumn{3}{|c|}{ No TVC } & \multicolumn{3}{|c|}{ No TVC Random } & \multicolumn{3}{|c|}{ TVC Stratified } \\
\hline & H.R. & $z$ & & H.R. & $z$ & & H.R. & $z$ & \\
\hline \multicolumn{10}{|c|}{ Country of residence of applicants (Reference $=$ France) } \\
\hline AT & 1,04 & 2,71 & $(* *)$ & 1,04 & 0,94 & & 1,02 & 0,59 & \\
\hline AU & 0,83 & $-13,03$ & $(* *)$ & 0,88 & $-2,78$ & $(* *)$ & 0,88 & $-2,67$ & $(* *)$ \\
\hline $\mathrm{BE}$ & 0,99 & $-0,47$ & & 0,99 & $-0,22$ & & 0,99 & $-0,38$ & \\
\hline CA & 1,02 & 1,52 & & 0,99 & $-0,15$ & & 1,01 & 0,22 & \\
\hline $\mathrm{CH}$ & 1,03 & 3,38 & $(* *)$ & 1,05 & 2,10 & $(*)$ & 1,04 & 1,78 & \\
\hline $\mathrm{DE}$ & 1,00 & $-0,07$ & & 1,02 & 1,00 & & 1,01 & 0,92 & \\
\hline DK & 0,89 & $-6,65$ & $(* *)$ & 0,83 & $-3,35$ & $(* *)$ & 0,83 & $-3,38$ & $(* *)$ \\
\hline ES & 1,04 & 1,99 & $\left({ }^{*}\right)$ & 1,00 & $-0,06$ & & 0,96 & $-0,83$ & \\
\hline $\mathrm{FI}$ & 0,79 & $-17,28$ & $(* *)$ & 0,76 & $-5,70$ & $(* *)$ & 0,75 & $-5,84$ & $(* *)$ \\
\hline GB & 1,05 & 7,50 & $(* *)$ & 1,07 & 3,44 & $(* *)$ & 1,05 & 2,65 & $(* *)$ \\
\hline IL & 1,05 & 2,45 & $\left({ }^{*}\right)$ & 1,00 & 0,01 & & 1,04 & 0,68 & \\
\hline IT & 1,04 & 4,64 & $(* *)$ & 1,03 & 1,49 & & 1,00 & $-0,02$ & \\
\hline$J P$ & 0,82 & $-38,66$ & $(* *)$ & 0,83 & $-11,64$ & $(* *)$ & 0,82 & $-12,12$ & $(* *)$ \\
\hline $\mathrm{KR}$ & 0,93 & $-3,51$ & $(* *)$ & 0,94 & $-0,98$ & & 0,93 & $-1,04$ & \\
\hline $\mathrm{NL}$ & 1,06 & 7,36 & $(* *)$ & 1,05 & 2,36 & $\left({ }^{*}\right)$ & 1,07 & 2,80 & $(* *)$ \\
\hline SE & 1,04 & 4,55 & $\left({ }^{* *}\right)$ & 0,97 & $-1,09$ & & 0,96 & $-1,32$ & \\
\hline US & 0,86 & $-15,07$ & $\left({ }^{* *}\right)$ & 0,85 & $-5,00$ & $(* *)$ & 0,85 & $-4,99$ & $(* *)$ \\
\hline RoW & 0,93 & $-14,09$ & $(* *)$ & 0,95 & $-3,63$ & $(* *)$ & 0,95 & $-3,33$ & $(* *)$ \\
\hline \multicolumn{10}{|c|}{ Time dummies (Reference $=1990)$} \\
\hline 1980 & 1,24 & 22,60 & $(* *)$ & 1,19 & 6,09 & $(* *)$ & 1,23 & 7,47 & $(* *)$ \\
\hline 1981 & 1,19 & 19,45 & $\left({ }^{* *}\right)$ & 1,17 & 6,11 & $(* *)$ & 1,21 & 7,30 & $(* *)$ \\
\hline 1982 & 1,16 & 17,29 & $(* *)$ & 1,13 & 5,04 & $(* *)$ & 1,17 & 6,16 & $(* *)$ \\
\hline 1983 & 1,10 & 11,91 & $(* *)$ & 1,08 & 3,32 & $(* *)$ & 1,11 & 4,44 & $(* *)$ \\
\hline 1984 & 1,08 & 9,69 & $\left({ }^{* *}\right)$ & 1,03 & 1,39 & & 1,05 & 2,30 & $\left({ }^{*}\right)$ \\
\hline 1985 & 1,04 & 5,26 & $\left({ }^{* *}\right)$ & 1,02 & 1,04 & & 1,04 & 1,69 & \\
\hline 1986 & 0,91 & $-11,90$ & $(* *)$ & 0,91 & $-3,87$ & $(* *)$ & 0,92 & $-3,42$ & $(* *)$ \\
\hline 1987 & 0,96 & $-4,86$ & $\left({ }^{* *}\right)$ & 0,96 & $-1,88$ & & 0,96 & $-1,56$ & \\
\hline 1988 & 0,96 & $-4,88$ & $(* *)$ & 0,96 & $-1,65$ & & 0,97 & $-1,35$ & \\
\hline 1989 & 0,98 & $-3,07$ & $(* *)$ & 0,95 & $-2,46$ & $(*)$ & 0,95 & $-2,14$ & $(*)$ \\
\hline 1991 & 0,99 & $-1,71$ & & 0,96 & $-1,89$ & & 0,96 & $-1,99$ & $(*)$ \\
\hline 1992 & 0,97 & $-4,07$ & $(* *)$ & 0,95 & $-2,13$ & $(*)$ & 0,96 & $-1,94$ & \\
\hline 1993 & 0,90 & $-12,88$ & $(* *)$ & 0,88 & $-5,53$ & $(* *)$ & 0,89 & $-5,22$ & $(* *)$ \\
\hline 1994 & 0,81 & $-25,96$ & $\left({ }^{* *}\right)$ & 0,80 & $-9,79$ & $(* *)$ & 0,81 & $-9,08$ & $(* *)$ \\
\hline 1995 & 0,72 & $-42,20$ & $(* *)$ & 0,72 & $-13,93$ & $(* *)$ & 0,74 & $-13,03$ & $(* *)$ \\
\hline 1996 & 0,66 & $-54,50$ & $(* *)$ & 0,65 & $-18,23$ & $(* *)$ & 0,67 & $-16,85$ & $(* *)$ \\
\hline 1997 & 0,67 & $-56,47$ & $(* *)$ & 0,66 & $-17,72$ & $(* *)$ & 0,69 & $-15,88$ & $(* *)$ \\
\hline 1998 & 0,77 & $-37,16$ & $(* *)$ & 0,77 & $-11,38$ & $(* *)$ & 0,81 & $-9,16$ & $(* *)$ \\
\hline 1999 & 1,07 & 9,39 & $(* *)$ & 1,05 & 2,17 & $(*)$ & 1,12 & 5,01 & $(* *)$ \\
\hline 2000 & 1,69 & 74,08 & $(* *)$ & 1,67 & 22,39 & $(* *)$ & 1,77 & 24,93 & $(* *)$ \\
\hline \multicolumn{10}{|l|}{ Model } \\
\hline \# Subjects & & 34860 & & & 13566 & & & 3566 & \\
\hline \# Failures & & 9924 & & & 74179 & & & 4179 & \\
\hline Log likelihood & & 36509 & & & 585214 & & & 83742 & \\
\hline LR $\operatorname{chi}^{2}\left(\mathrm{P}>\mathrm{chi}^{2}\right)$ & & $50(0,00)$ & & & $259(0,00)$ & & & $22(0,00)$ & \\
\hline
\end{tabular}

Cox Regression Model with Time-varying Covariates (TVC) - Breslow method for ties Stratified by reason for lapse unless otherwise specified (EPO Filings 1980-2000) 10\% Random Sample 


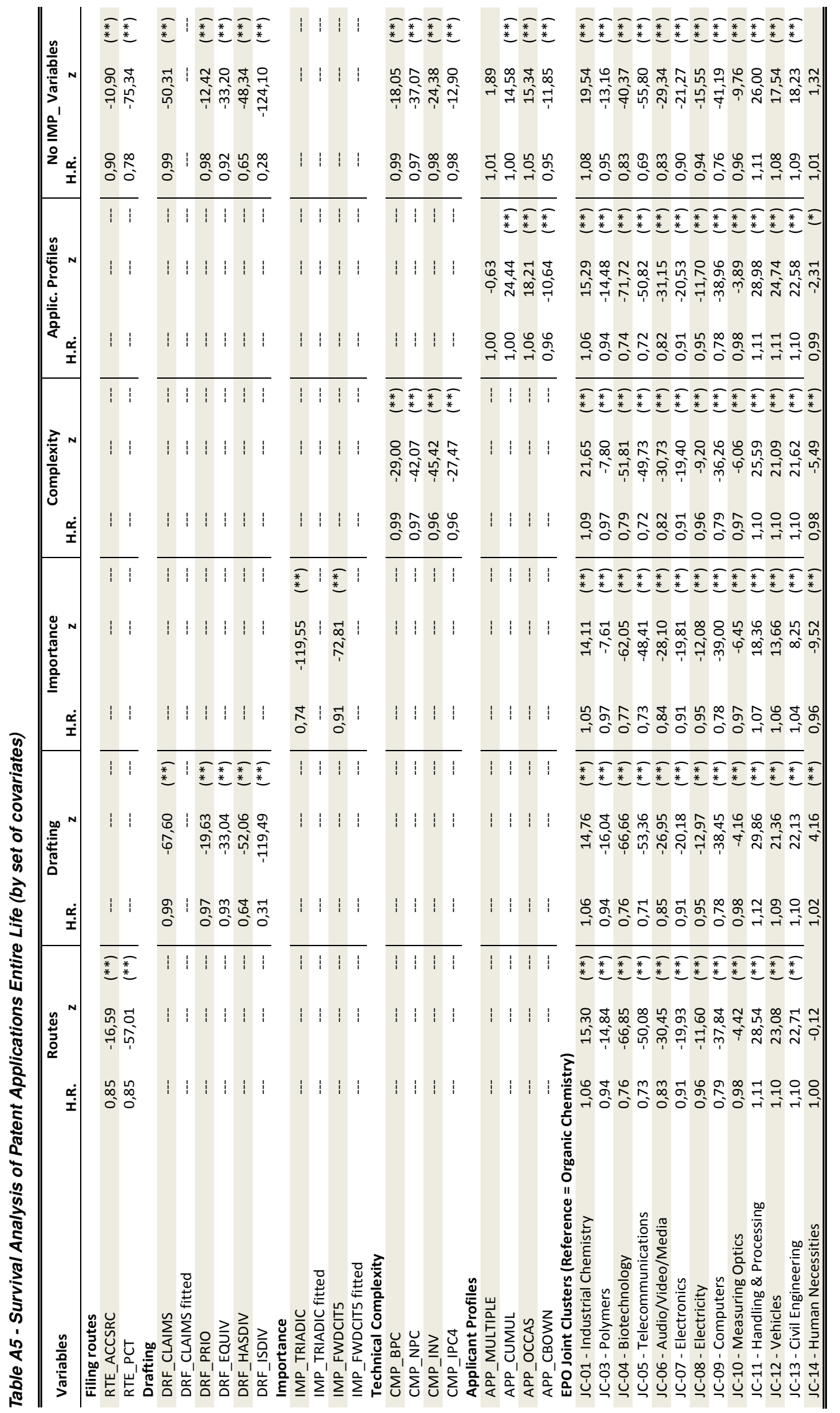




\section{琵}

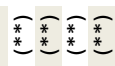

ำ ๆ

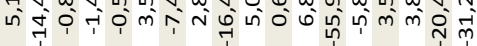

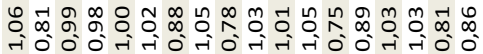

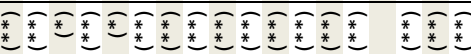

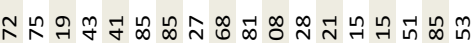

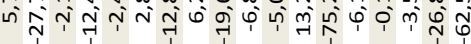

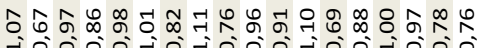

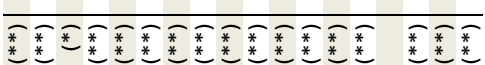

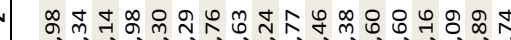

mं

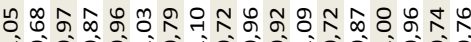

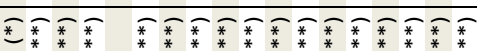

$\check{\Xi}^{2}$

๑กิ

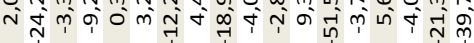

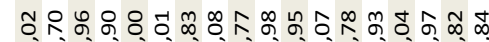

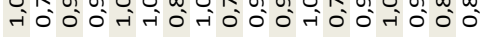

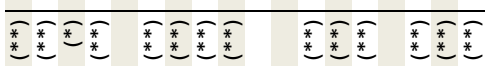

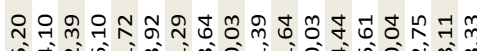

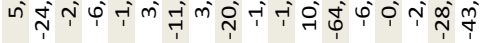

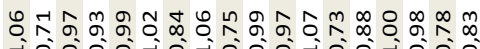

$\stackrel{\dot{x}}{\dot{x}}$

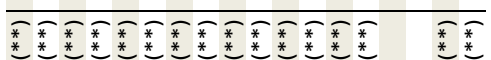

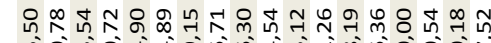

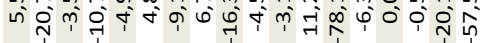

\begin{tabular}{l}
0 \\
\hdashline \\
0
\end{tabular}

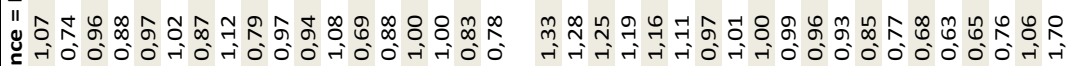

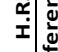

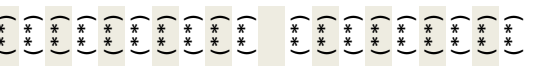

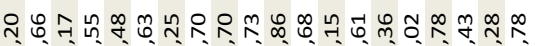

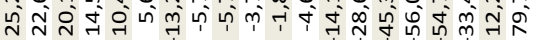

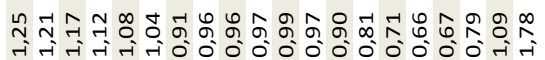

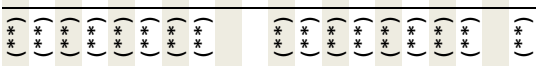

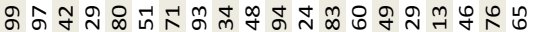

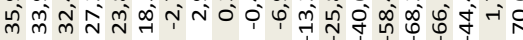

色

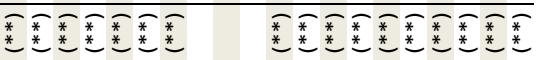

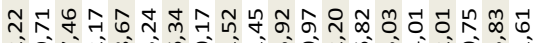

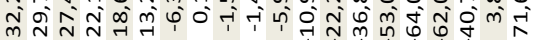

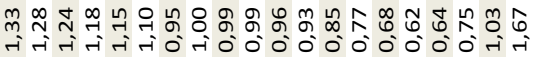

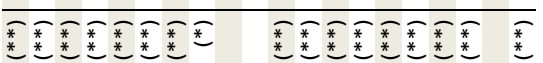

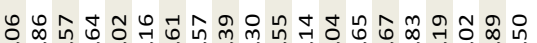

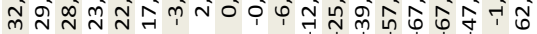

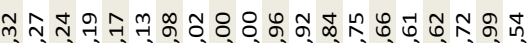

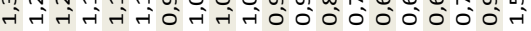

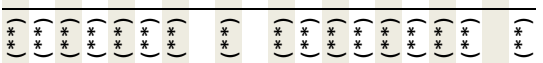
ํำ

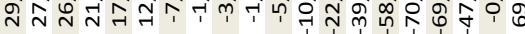

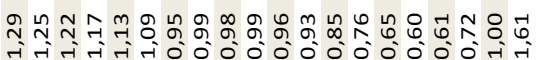

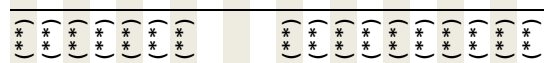

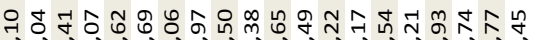

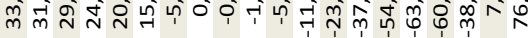
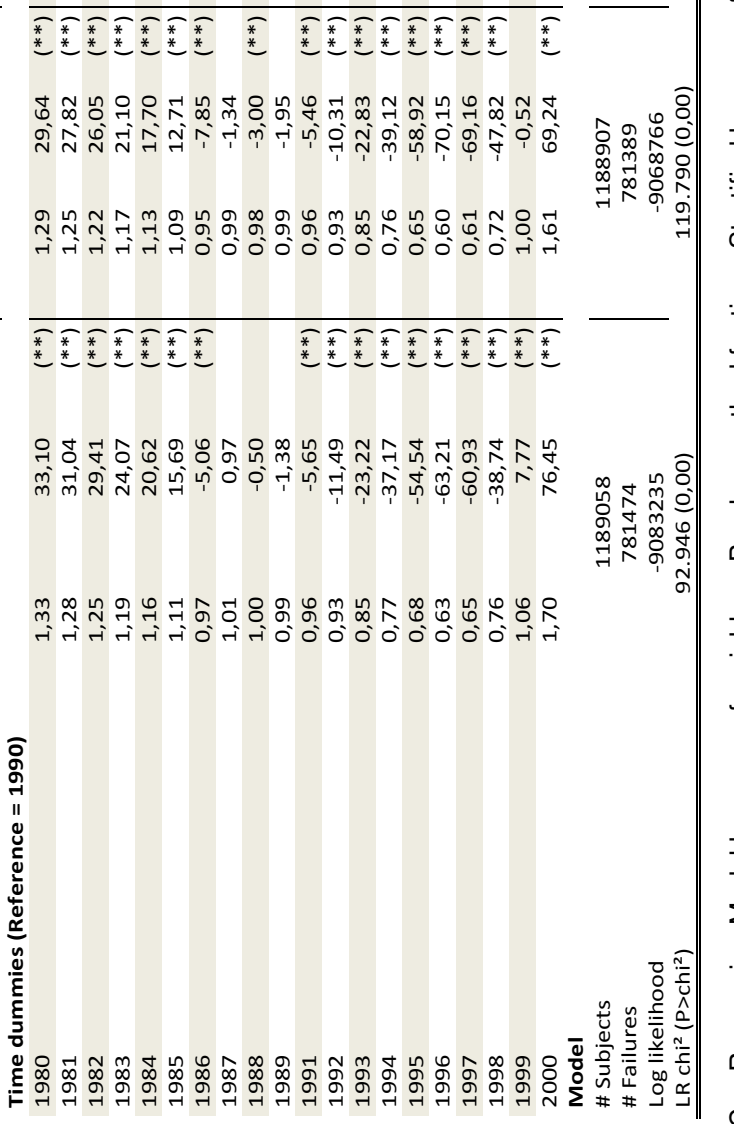
Table A6 - Survival Analysis of Patent Applications Entire Life by Type of Applicant

\begin{tabular}{|c|c|c|c|c|c|c|c|c|c|}
\hline \multirow{2}{*}{ Variables } & \multicolumn{3}{|c|}{ Occasional } & \multicolumn{3}{|c|}{ Others } & \multicolumn{3}{|c|}{ Academic } \\
\hline & H.R. & $\mathbf{z}$ & & H.R. & $z$ & & H.R. & z & \\
\hline \multicolumn{10}{|l|}{ Filing routes } \\
\hline RTE_ACCSRC & 0,85 & $-7,82$ & $(* *)$ & 0,92 & $-7,42$ & $(* *)$ & 0,95 & $-0,90$ & \\
\hline RTE_PCT & 0,72 & $-42,86$ & $(* *)$ & 0,81 & $-54,63$ & $(* *)$ & 0,71 & $-14,89$ & $(* *)$ \\
\hline \multicolumn{10}{|l|}{ Drafting } \\
\hline DRF_CLAIMS & 0,99 & $-19,10$ & $(* *)$ & 0,99 & $-35,73$ & $(* *)$ & 1,00 & $-6,33$ & $(* *)$ \\
\hline DRF_CLAIMS fitted & --- & --- & --- & --- & --- & --- & --- & --- & --- \\
\hline DRF_PRIO & 1,02 & 3,53 & $(* *)$ & 0,99 & $-3,97$ & $(* *)$ & 0,97 & $-1,94$ & \\
\hline DRF_EQUIV & 0,95 & $-6,31$ & $(* *)$ & 0,93 & $-27,85$ & $(* *)$ & 0,89 & $-8,18$ & $(* *)$ \\
\hline DRF_HASDIV & 0,63 & $-12,17$ & $(* *)$ & 0,67 & $-42,52$ & $(* *)$ & 0,65 & $-9,33$ & $(* *)$ \\
\hline DRF_ISDIV & 0,23 & $-41,35$ & $(* *)$ & 0,30 & $-112,12$ & $(* *)$ & 0,20 & $-25,61$ & $(* *)$ \\
\hline \multicolumn{10}{|l|}{ Importance } \\
\hline IMP_TRIADIC & 0,77 & $-38,91$ & $(* *)$ & 0,77 & $-89,86$ & $(* *)$ & 0,74 & $-16,57$ & $(* *)$ \\
\hline IMP_TRIADIC fitted & --- & --- & --- & --- & --- & --- & --- & --- & --- \\
\hline IMP_FWDCIT5 & 0,93 & $-20,60$ & $(* *)$ & 0,92 & $-55,95$ & $(* *)$ & 0,93 & $-11,10$ & $(* *)$ \\
\hline IMP_FWDCIT5 fitted & --- & --- & --- & --- & --- & --- & --- & --- & --- \\
\hline \multicolumn{10}{|l|}{ Technical Complexity } \\
\hline CMP_BPC & 0,99 & $-8,28$ & $(* *)$ & 0,99 & $-16,16$ & $(* *)$ & 0,99 & $-1,79$ & \\
\hline CMP_NPC & 0,97 & $-12,21$ & $(* *)$ & 0,98 & $-28,14$ & $(* *)$ & 0,98 & $-7,55$ & $(* *)$ \\
\hline CMP_INV & 0,97 & $-11,12$ & $(* *)$ & 0,99 & $-13,74$ & $(* *)$ & 1,00 & $-0,36$ & \\
\hline CMP_IPC4 & 0,97 & $-6,80$ & $(* *)$ & 0,99 & $-3,04$ & $(* *)$ & 0,96 & $-4,42$ & $(* *)$ \\
\hline \multicolumn{10}{|l|}{ Applicant Profiles } \\
\hline APP_MULTIPLE & 1,05 & 4,74 & $(* *)$ & 0,99 & $-1,64$ & & 0,96 & $-1,83$ & \\
\hline APP_CUMUL & -- & --- & --- & 1,00 & 20,95 & $(* *)$ & 1,00 & $-2,03$ & $(*)$ \\
\hline APP_OCCAS & --- & --- & --- & --- & --- & --- & 0,97 & $-1,33$ & \\
\hline APP_CBOWN & 0,93 & $-6,00$ & $(* *)$ & 0,95 & $-10,64$ & $(* *)$ & 0,98 & $-0,50$ & \\
\hline \multicolumn{10}{|c|}{ EPO Joint Clusters (Reference = Organic Chemistry) } \\
\hline JC-01 - Industrial Chemistry & 1,03 & 2,86 & $(* *)$ & 1,08 & 18,84 & $(* *)$ & 1,11 & 3,82 & $(* *)$ \\
\hline JC-03 - Polymers & 0,89 & $-9,46$ & $(* *)$ & 0,96 & $-8,01$ & $(* *)$ & 1,06 & 1,53 & \\
\hline JC-04 - Biotechnology & 0,85 & $-14,59$ & $(* *)$ & 0,86 & $-28,77$ & $(* *)$ & 0,84 & $-7,51$ & $(* *)$ \\
\hline JC-05 - Telecommunications & 0,81 & $-10,22$ & $(* *)$ & 0,67 & $-55,64$ & $(* *)$ & 0,83 & $-2,11$ & $(*)$ \\
\hline JC-06 - Audio/Video/Media & 0,95 & $-2,86$ & $(* *)$ & 0,82 & $-28,87$ & $(* *)$ & 0,91 & $-1,62$ & \\
\hline JC-07 - Electronics & 0,94 & $-4,37$ & $(* *)$ & 0,90 & $-21,25$ & $(* *)$ & 1,15 & 2,61 & $(* *)$ \\
\hline JC-08 - Electricity & 0,96 & $-3,47$ & $(* *)$ & 0,92 & $-17,75$ & $(* *)$ & 1,03 & 0,78 & \\
\hline JC-09 - Computers & 0,89 & $-7,46$ & $(* *)$ & 0,72 & $-43,62$ & $(* *)$ & 0,82 & $-3,09$ & $(* *)$ \\
\hline JC-10 - Measuring Optics & 0,95 & $-4,20$ & $(* *)$ & 0,95 & $-10,95$ & $(* *)$ & 1,06 & 2,49 & $(*)$ \\
\hline JC-11 - Handling \& Processing & 1,13 & 14,72 & $(* *)$ & 1,07 & 14,43 & $(* *)$ & 1,17 & 3,86 & $(* *)$ \\
\hline JC-12 - Vehicles & 1,12 & 11,60 & $(* *)$ & 1,04 & 6,95 & $(* *)$ & 1,21 & 3,65 & $(* *)$ \\
\hline JC-13 - Civil Engineering & 1,06 & 6,32 & $(* *)$ & 1,04 & 6,49 & $(* *)$ & 1,18 & 3,95 & $(* *)$ \\
\hline JC-14 - Human Necessities & 1,09 & 10,31 & $(* *)$ & 0,95 & $-9,19$ & $(* *)$ & 0,89 & $-3,51$ & $(* *)$ \\
\hline
\end{tabular}


Table A6 - (continued)

\begin{tabular}{|c|c|c|c|c|c|c|c|c|c|}
\hline \multirow{2}{*}{ Variables } & \multicolumn{3}{|c|}{ Occasional } & \multicolumn{3}{|c|}{ Others } & \multicolumn{3}{|c|}{ Academic } \\
\hline & H.R. & $\mathbf{z}$ & & H.R. & z & & H.R. & z & \\
\hline \multicolumn{10}{|c|}{ Country of residence of applicants (Reference $=$ France) } \\
\hline AT & 1,00 & 0,01 & & 1,04 & 3,00 & $(* *)$ & 0,78 & $-1,52$ & \\
\hline $\mathrm{AU}$ & 0,85 & $-7,58$ & $(* *)$ & 0,83 & $-7,98$ & $(* *)$ & 0,82 & $-3,41$ & $(* *)$ \\
\hline $\mathrm{BE}$ & 1,02 & 0,64 & & 0,97 & $-1,80$ & & 1,38 & 4,79 & $(* *)$ \\
\hline $\mathrm{CA}$ & 1,01 & 0,58 & & 1,02 & 1,04 & & 1,16 & 3,00 & $(* *)$ \\
\hline $\mathrm{CH}$ & 0,97 & $-2,00$ & $\left({ }^{*}\right)$ & 1,04 & 4,68 & $(* *)$ & 1,44 & 5,46 & $(* *)$ \\
\hline DE & 0,95 & $-4,51$ & $(* *)$ & 1,01 & 2,60 & $(* *)$ & 1,12 & 2,52 & $(*)$ \\
\hline DK & 0,94 & $-2,16$ & $\left({ }^{*}\right)$ & 0,86 & $-7,25$ & $(* *)$ & 0,98 & $-0,17$ & \\
\hline ES & 1,02 & 0,95 & & 0,98 & $-0,76$ & & 1,07 & 0,67 & \\
\hline $\mathrm{FI}$ & 0,78 & $-8,08$ & $\left({ }^{* *}\right)$ & 0,79 & $-13,10$ & $(* *)$ & 1,69 & 2,50 & $\left({ }^{*}\right)$ \\
\hline GB & 0,99 & $-0,49$ & & 1,06 & 8,92 & $(* *)$ & 1,10 & 2,42 & $\left({ }^{*}\right)$ \\
\hline IL & 1,03 & 1,14 & & 1,05 & 1,90 & & 1,01 & 0,07 & \\
\hline IT & 1,05 & 3,90 & $(* *)$ & 1,01 & 0,64 & & 1,11 & 1,39 & \\
\hline$J P$ & 0,89 & $-8,22$ & $(* *)$ & 0,82 & $-33,97$ & $\left({ }^{* *}\right)$ & 0,87 & $-3,37$ & $(* *)$ \\
\hline $\mathrm{KR}$ & 1,02 & 0,45 & & 0,90 & $-4,23$ & $(* *)$ & 1,15 & 1,80 & \\
\hline NL & 0,96 & $-2,40$ & $(*)$ & 1,08 & 9,44 & $(* *)$ & 1,31 & 4,76 & $(* *)$ \\
\hline SE & 1,02 & 1,64 & & 1,03 & 2,70 & $(* *)$ & 1,36 & 6,64 & $(* *)$ \\
\hline US & 0,86 & $-8,01$ & $(* *)$ & 0,86 & $-12,22$ & $(* *)$ & 1,07 & 0,50 & \\
\hline RoW & 0,86 & $-13,95$ & $(* *)$ & 0,96 & $-8,34$ & $(* *)$ & 0,99 & $-0,43$ & \\
\hline \multicolumn{10}{|c|}{ Time dummies $($ Reference $=1990)$} \\
\hline 1980 & 1,18 & 8,15 & $(* *)$ & 1,25 & 21,84 & $(* *)$ & 0,97 & $-0,38$ & \\
\hline 1981 & 1,13 & 6,63 & $(* *)$ & 1,20 & 19,63 & $(* *)$ & 0,95 & $-0,67$ & \\
\hline 1982 & 1,09 & 4,47 & $(* *)$ & 1,17 & 17,90 & $(* *)$ & 1,05 & 0,67 & \\
\hline 1983 & 1,05 & 2,92 & $(* *)$ & 1,11 & 12,76 & $(* *)$ & 0,93 & $-1,09$ & \\
\hline 1984 & 1,01 & 0,74 & & 1,09 & 10,71 & $(* *)$ & 0,95 & $-0,84$ & \\
\hline 1985 & 0,98 & $-0,87$ & & 1,05 & 6,28 & $(* *)$ & 0,99 & $-0,18$ & \\
\hline 1986 & 0,89 & $-6,53$ & $(* *)$ & 0,91 & $-11,57$ & $(* *)$ & 0,94 & $-1,23$ & \\
\hline 1987 & 0,94 & $-3,70$ & $(* *)$ & 0,97 & $-4,11$ & $(* *)$ & 0,95 & $-0,95$ & \\
\hline 1988 & 0,94 & $-3,63$ & $(* *)$ & 0,97 & $-4,35$ & $(* *)$ & 1,02 & 0,46 & \\
\hline 1989 & 0,97 & $-1,58$ & & 0,98 & $-3,06$ & $(* *)$ & 1,04 & 0,76 & \\
\hline 1991 & 1,01 & 0,63 & & 0,99 & $-1,94$ & & 0,91 & $-1,84$ & \\
\hline 1992 & 0,95 & $-2,98$ & $(* *)$ & 0,98 & $-3,07$ & $(* *)$ & 0,82 & $-3,71$ & $(* *)$ \\
\hline 1993 & 0,89 & $-6,68$ & $(* *)$ & 0,91 & $-11,77$ & $(* *)$ & 0,78 & $-4,67$ & $(* *)$ \\
\hline 1994 & 0,81 & $-12,18$ & $(* *)$ & 0,82 & $-24,48$ & $(* *)$ & 0,70 & $-6,85$ & $(* *)$ \\
\hline 1995 & 0,73 & $-17,83$ & $(* *)$ & 0,71 & $-40,88$ & $(* *)$ & 0,69 & $-7,17$ & $(* *)$ \\
\hline 1996 & 0,67 & $-22,84$ & $(* *)$ & 0,66 & $-50,74$ & $(* *)$ & 0,72 & $-6,36$ & $(* *)$ \\
\hline 1997 & 0,68 & $-22,45$ & $(* *)$ & 0,65 & $-51,43$ & $(* *)$ & 0,88 & $-2,58$ & $(*)$ \\
\hline 1998 & 0,79 & $-14,38$ & $(* *)$ & 0,76 & $-34,07$ & $(* *)$ & 1,18 & 3,44 & $(* *)$ \\
\hline 1999 & 1,01 & 0,76 & & 1,06 & 7,73 & $(* *)$ & 1,63 & 9,87 & $(* *)$ \\
\hline 2000 & 1,45 & 21,86 & $(* *)$ & 1,73 & 67,38 & $(* *)$ & 2,86 & 20,57 & $(* *)$ \\
\hline \multicolumn{10}{|l|}{ Model } \\
\hline \# Subjects & \multicolumn{3}{|c|}{186639} & \multicolumn{3}{|c|}{926567} & \multicolumn{3}{|c|}{25293} \\
\hline \# Failures & \multicolumn{3}{|c|}{135493} & \multicolumn{3}{|c|}{591303} & \multicolumn{3}{|c|}{15497} \\
\hline Log likelihood & \multicolumn{3}{|c|}{-1329447} & \multicolumn{3}{|c|}{-6698188} & \multicolumn{3}{|c|}{-117129} \\
\hline $\operatorname{LR~Chi~}^{2}\left(P>\operatorname{chi}^{2}\right)$ & \multicolumn{3}{|c|}{$25.912(0,00)$} & \multicolumn{3}{|c|}{$108.632(0,00)$} & \multicolumn{3}{|c|}{$5.402(0,00)$} \\
\hline
\end{tabular}

